\title{
Publication Records of Faculty Promoted to Professor: Evidence from the UK Accounting and Finance Academic Community
}

\author{
Vivien Beattie* and Alan Goodacre** \\ * Professor of Accounting, University of Glasgow \\ ** Professor of Accounting and Finance, University of Stirling
}

11 July 2010

\begin{abstract}
This study investigates the publication profiles of 140 accounting and finance faculty promoted to the senior rank of professor at UK and Irish universities during the period 1992 to 2007. On average, approximately 9 papers in Association of Business Schools (ABS) (2008)-listed journals, with 5 at the highest $3 * / 4 *$ quality levels in a portfolio of 20 outputs are required for promotion to professor. Multivariate analysis provides evidence that publication requirements in terms of ABS ranked journal papers have increased over time, an effect attributed to the government research assessment exercise. There is no evidence that requirements differ for: internal versus external promotion, male versus female candidates; accounting versus finance professors, research intensity of institution peer group; or government research ranking of unit. There is also no evidence of a substitution effect in relation to increased recent publication history, quantity of non-ABS outputs or soleauthorship, all of which show a significant complementary effect. It is noted that there is very limited overlap in the UK and US publication journal sets, suggesting underlying geographically-based paradigm differences. The benchmarks provided in this study are informative in a range of decision settings: recruitment; those considering making an application for promotion to a chair and those involved in promotion panels; cross-disciplinary comparisons; and resource allocation. The evidence presented also contributes to the emerging policy debates concerning the aging demographic profile of accounting faculty, the management of academic labour and the Research Excellence Framework.
\end{abstract}

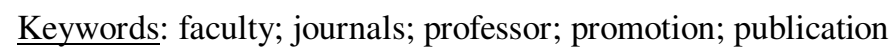

JEL classifications: M40, M49

Professor Alan Goodacre

Accounting and Finance Division, Stirling Management School, University of Stirling, Stirling FK9 4LA, UK

Tel: +44 (0)1786 467291; Email alan.goodacre@stir.ac.uk

Professor Vivien Beattie

Dept. of Accounting and Finance, University of Glasgow, West Quadrangle, Main Building, University Avenue, Glasgow G12 8QQ, UK

Tel.+44 (0)141330 6855; Email V.Beattie@accfin.gla.ac.uk

\section{Acknowledgements}

Special thanks go to Elizabeth Davie for her advice and assistance in designing the Access database and to Nurwati AhmadZaluki and others for valuable contributions in data collection. 


\section{Publication Records of Faculty Promoted to Professor: Evidence from the UK Accounting and Finance Academic Community}

\section{INTRODUCTION}

Academics have an ongoing interest in the publication records of their peer group, at the level of both the individual academic and the academic unit (e.g. division, department or school). At the theoretical level, this is because publication and subsequent citation are primary indicators of academic reputation at both the individual and institutional level (Beattie and Ryan, 1989: 267). On a more practical level, this is because we are periodically required to take decisions that rely on the evaluation of publication records. These may be personal career decisions, such as in which academic institution to seek appointment or when to seek promotion or decisions regarding the career of others, as in the case of appointment panels, promotion committees and probationary evaluations (e.g. Glover et al., 2006; Beattie and Goodacre, 2004; Fogarty et al., 2004).

In the UK, the US and many other countries, there is growing concern regarding the demographics of the accounting and finance academic community. A recent US study documents trends from 1993 to 2004, showing an ageing and shrinking community of faculty in the face of rising student numbers (AAA, 2008). Another recent US study investigated the supply and demand for accounting PhDs and concluded that there will be an overall shortage in new accounting faculty over the next ten years (AACSB, 2003; Plumlee et al. 2005; 2006). Similar concerns have been voiced by UK academic accounting and finance groups such as the Conference of Professors of Accounting and Finance (CPAF). In the most recent triennial survey of UK university managers concerning staff recruitment and retention (UCEA, 2008), accounting and finance is highlighted among the subject areas that consistently experience recruitment shortages. The academic labour market for faculty positions is thus very thin, with the consequence that recruitment and retention issues are very high on the agenda for senior academic managers.

The higher education sectors in many developed countries have seen significant growth and change over the last few decades (Saravanamuthu and Tinker, 2002). In the UK, government policy in the early 1990s sought to increase the percentage of school leavers going on the university from approximately $12 \%$ to $40 \%$. To achieve this increase in capacity, 'new' universities were created by the abolition of the 'binary divide' between polytechnic institutions and universities in 1992, together with a few degree-granting colleges. Over 100 degree-awarding institutions now exist in the UK (British Accounting Review (BAR) Research Register, 2008). However, there continue to be two fundamentally different types of higher education institution within the UK, reflecting the relative emphasis placed on research activity. The number of accounting and finance professors increased from 37 in 1982 to 247 in 2004 with this rank representing a growing proportion of faculty (Brown et al., 2007). The UK faculty ranking system has three main levels: lecturer, senior lecturer and professor. 
These are broadly comparable to the US designations of assistant professor, associate professor and full professor. Promotion to senior lecturer is normally based on performance in the three areas of teaching, research and service, with excellence in any two out of three and satisfactory performance in the third area being required for internal advancement. Promotion to a professorial chair is normally related explicitly to research performance. Tenure is the norm in the UK for appointments at all levels. For over 20 years, government funding has been allocated to universities based on the outcomes of periodic peer-review based Research Assessment Exercises (RAE) which evaluate research quality. The most recent results were in 2008 (RAE, 2008); the next round (now renamed Research Excellence Framework) (REF, 2009) is expected in 2013. Institutional reputation and hence income from student numbers is strongly linked to these published outcomes, providing strong institutional incentives in respect of research.

Commentators in many countries have noted the increasing pressure to publish in what are deemed by evaluators to be high-quality journals (e.g. Chow et al., 2008; Gendron, 2008; Brown et al., 2007; Reinstein and Calderon, 2006; Brinn et al., 2001; Van Fleet et al., 2000; Woodside, 2009). Consequently, the use of formal quality lists such as the Financial Times list, the Association of Business Schools list of top journals (ABS, 2008; 2009), and Harzing's Journal Quality List (Harzing, 2008) has increased. In response to this pressure, papers are appearing that criticise the 'commodification' of academic labour and the corresponding desire of government and institutions to 'control' and 'manage' scholarly activity (e.g. Gendron, 2008; Tinker, 2006; Gray et al., 2002; Parker et al., 1998; Willmott, 1995; Puxty et al., 1994; Saravanamuthu and Tinker, 2002). It is believed that the pressure to publish in top ranked journals is leading to 'greater uniformity of the research process', 'career instrumentalism' and an 'institutionalised approach to research' (Hopwood, 2008: 87 and 90).

These two trends (the thin market for faculty and the increased pressure to publish) have the potential to create offsetting forces impacting on promotion benchmarks over time. While publication rates in top journals increased until 2000, partly attributable to RAE effects (Brown et al., 2007), there is prima facie pressure to promote faculty early in the competition to recruit/retain individuals.

The purpose of this study is to present, for the first time, a description and analysis of promotion (to the senior rank of professor) benchmarks prevailing at UK and Irish accounting and finance higher education institutions during the period 1992 to 2007. The paper makes three main contributions. First, promotion publication benchmarks are informative in other decision settings, such as recruitment, promotion, cross-disciplinary comparisons and resource allocation. Second, analysis allows the examination of factors thought to influence promotion hurdles. Finally, the evidence presented also offers critical insight into current policy debates concerning the aging demographic profile of accounting faculty, the management of academic labour and the Research Excellence Framework (REF). 
The results reported are based on the data contained in various editions of the British Accounting Review Research Register, (hereafter the Register; various years). This publication covers both the accounting and finance disciplines because they are closely related and are frequently located within the same organisational unit within institutions (albeit increasingly as part of a larger business school). The Register includes all the self-reported publications of staff in the UK and Ireland. The publication records of successful professorial promotees are analysed by institution peer group, external versus internal promotion, gender, sub-discipline, time period, and recency of publication. The publication record characteristics considered include quantity measures; journal versus non-journal outputs; and journal quality ranking. Both univariate and multivariate analysis is undertaken. ${ }^{1}$

The remainder of this paper is structured as follows. Section two includes five sub-sections covering various strands of relevant literature. Section three develops specific research questions to be addressed. The fourth section describes the methods, in particular how the database was constructed from the Registers as initial data sources. Results are presented and discussed in section five. A final section summarises and concludes.

\section{PRIOR LITERATURE}

In this section, five diverse strands of relevant literature are reviewed: the academic reward system and the impact of managerialism; the pre-eminent role of research in promotion decisions and the value given by assessors to different forms of publication; journal quality ranking studies; prior empirical studies of accounting and finance faculty publication records and promotion benchmarks; and gender influences.

\subsection{The academic reward system and the impact of managerialism}

Publication and subsequent citation produce the reputational capital that underlies the academic reward system, with promotion representing a key reward. Publication and citation practices are inextricably bound up in the processes underlying the development of scholarly knowledge. Studies of the development of accounting thought have generally either been atheoretical or have adopted Kuhn's model of scientific growth. The value of Kuhn's work lies in his recognition that non-cognitive factors, in particular social, cultural, institutional, and external factors, can all be involved in scholarly knowledge development. Beattie and Davie (2006) propose a composite neo-Kuhnian model and use author cocitation analysis to empirically map the literature structure of the accounting discipline. Findings indicate the existence of geographically-based competing research elites, consistent with the findings of Lukka and Kasanen (1996), who distinguish a dominant U.S. elite from an emerging, mostly European elite. This has been attributed to paradigm differences, with US journals favouring the financial economics paradigm, 
with its attendant methodology of positivism, while non-US journals have more diverse content and methodological heterogeneity (Raffournier and Schatt, 2010).

In recent years, many countries, including the UK, have introduced managerialist strategies into the higher education sector that seek to control activity using a limited range of quantifiable performance measures, such as percentage of first class honours degrees and number of refereed journal publications. Driven partly by the reduction in public spending on the sector, universities have undergone processes of corporatisation and economic rationalism, resulting in the customerisation of teaching activities and the commodification of academic labour (Saravanamuthu and Tinker, 2002).

The use of a narrow set of research performance measures is likely to have undesirable unintended behavioural consequences, such as a shift away from high-risk, innovative or longer-term projects (Neumann and Guthrie, 2002) and the displacement of knowledge-based values in favour of commercial values (Parker, 2002). The change in environment faced by researchers is such that Moizer (2009) characterises publishing in journals as a 'game', played by authors, reviewers, editors and bureaucrats. He laments the facts that the original purpose of publishing, the advancement of knowledge, has been lost in the competition to publish in journals designated 'A grade' which bring rewards in the form of promotion and increased salary.

In an interesting study, Wedlin (2006; 2007) investigates the role of classification mechanisms, such as business school rankings, on behaviour at the institutional, rather than individual, level. She shows how the existence of these rankings codifies an organisational template in the form of a set of standards that organisations seek to attain and which, in turn, creates isomorphic pressures.

\subsection{Pre-eminent role of research}

Scholarly activity involves three elements: teaching, research and service. Service includes administration and managerial roles internal to the institution as well as external roles such as journal editing, membership of professional committees, etc. (Gray et al., 2002). Academics operate in a 'publish or perish' environment. Hermanson (2008: 55-56) observes that 'research drives reputation, rewards, and opportunities far more than teaching or service. This appears to be true at the vast majority of universities in the U.S., even many of those with a teaching-oriented or balanced mission'. Glover et al. (2006: 196) also argue that research is the most important criterion for promotion. ${ }^{2}$ Outside the US, Parker et al., (1998) provide interview evidence from the UK and Australia that publication is viewed as the major element in the assessment of academics. Recent cross-disciplinary UK studies based on academic perceptions reinforce the finding that research holds a pre-eminent role in relation to teaching, especially in pre-1992 institutions (Young, 2006; Parker, 2008; Higher Education Academy, 2009). 
Several writers discuss the value of different forms of publication, such as refereed journal articles, research reports/monographs, research books, textbooks, chapters in books, refereed conference papers, and edited books and professional journal articles (e.g. Carmona, 2006; Beattie and Goodacre, 2004; Parker et al., 1998; and Beattie and Ryan, 1991). Carmona (2006: 241) presents evidence that books and research monographs exert a 'considerable impact on the diffusion of accounting research'. However, while the intrinsic value of outlets other than refereed journal articles is widely recognised, in practice it is refereed journal articles that seem to have greatest value. Moreover, in certain decision contexts, such as decision made in leading institutions or in relation to REF outputs to be submitted, this can be restricted to 'top' journals, and sometimes only those within the boundaries of the discipline. Carmona (2006: 246) argues that there are two opposing views concerning the importance of 'related-discipline' journals in assessments of research performance. One view is that academic reputations are based on publications that are likely to be read by their peers, hence related discipline publications are seen as less relevant. The other view is that, as an interdisciplinary discipline, publications in disciplines related to accounting and finance have comparable value. In this context, Christensen et al. (2002) find that US accounting faculty commonly use non-accounting journals as publication outlets and that this tendency increases throughout the career.

It should be noted, however, that the research element provides a necessary but not sufficient condition for promotion (Fishe, 1998). Even within the research domain, leadership in research, success in gaining research grant funding and successful $\mathrm{PhD}$ student supervision are other relevant aspects in many institutions. Outside the research domain, high quality teaching, academic service, management expertise (or potential) all feature to a greater or lesser extent in promotion decisions. The relative importance of each aspect often varies with the specific needs of the organisation at a particular point in time, the urgency of those needs as well as the research intensity of the university (Street et al., 1993; Higher Education Academy, 2009). These aspects are conditioned by a whole range of essentially random factors, including the characteristics of the set of applicants.

\subsection{Journal quality ranking studies}

Given the key role of academic journal articles in the scholarly communication network of many disciplines, it is perhaps unsurprising that journal rankings have emerged in response to the managerialism being introduced into the sector. The main approaches to such rankings are based on either citations or surveys of perceptions. ${ }^{3}$ Citation studies, which treat citations as objective indicators of influence, commonly use the Social Sciences Citation Index (SSCI) database (http://www.thomsonreuters.com/products_services/scientific/Social_Sciences_Citation_Index). The number of accounting and finance journals included in this database remains small, despite several new admissions in the last few years. A typical study in the finance discipline is Chan et al. (2000), who rank 59 journals using the SSCI. Perception studies typically ask respondents to rate journals on

their 'quality' (or an associated concept such as 'readability', 'value' and/or 'familiarity'). An 
illustrative comprehensive study by Ballas and Theoharakis (2003) obtained responses from 1,230 accounting academics located across the world. This study showed, inter alia, that perceptions are influenced by factors associated with geographic location.

Each of these approaches has limitations. Citation studies depend on the assumption that a citation is an objective indicator of influence, while perception studies may suffer from inherent biases such as a pre-disposition towards journals in which respondents publish. Given these limitations, it is perhaps understandable that rankings have emerged which collate the results from several separate ranking studies (e.g. ABS, 2008; Harzing, 2008). The present study makes use of the ABS (2008) quality groups. An advantage of this list is that it includes many journals outside the accounting and finance discipline, as it has been shown that UK academics in the accounting and finance community publish in a wide range of journals across many disciplines (Beattie and Goodacre, 2004).

\subsection{Accounting and finance faculty publication and promotion benchmarks}

Two recent descriptive studies of publication patterns within the UK and Irish academic accounting and finance community use the Register as a data source. Brown et al. (2007), a longitudinal study covering the 24-year period 1980 to 2003, find that per capita publication rates declined from 1998 . They argue that the publication pressures of the RAE (2001) assessment exercise contributed to the peak in the 'all journal articles' category in 2000. Beattie and Goodacre (2004) perform a more finegrained study of the two-year period 1998 to 1999. Inter alia, they find that the publication profile of professors from 'old' universities is distinct from that of professors from 'new' universities. The latter have, on average, a higher total number of publications but a lower number of top journal publications.

It is interesting that no generic 'theory of promotion' exists. ${ }^{4}$ This is perhaps due to relevant promotion criteria being occupation-specific. Normally, however, a two-stage process occurs: objective factors (match with job specification) prevail at the initial screening stage, whereas subjective factors such as collegiality take precedence at the second, interview stage. Additionally, specific factors such as 'strategic fit' with the academic unit's research specialisms, teaching needs, or leadership requirements, act as unpredictable influences on the final decision. To date, all published studies of promotion benchmarks in the accounting and finance disciplines are US based. Given the dominance of US journals and the fact that so few UK academics publish in the leading US journals ${ }^{5}$, the findings of these studies are likely to be of limited relevance to UK academics.

Glover et al. (2006) examine the publication records of 85 accounting faculty promoted to full professor at leading US institutions during the eight-year period 1995 to 2003 . The institutions considered are the top 75 accounting programmes, split into five equal-sized peer groups based on Trieschmann et al.'s ranking (2000). Outputs are split into six overlapping quality sets: top 3 accounting journals (top 3); top 3 accounting journals plus top 35 business journals in other disciplines 
(through top business); top six accounting journals plus top 35 business (through top 6), top 15 accounting journals plus top 35 business (through top 15), top 25 accounting journals plus top 35 business (through top 25); and all publications (including other journal outputs, books and monographs) (all). For each level of rank advancement, tercile means are reported by institution peer group and output set in a five by six matrix. It is suggested that the mean of the lower tercile proxies for the minimum research expectation for a given institutional peer group. It is found that, for the top peer group, the lower tercile means were 4.5 top 3 articles, 5.3 through top business articles, 7.0 through top 6 articles, 10.8 through top 15 articles, 12.6 through top 25 articles and 18.7 publications in all. The corresponding figures for the lowest institutional peer group were: 0.0, 0.0, 0.0, 1.0, 3.0 and 26.0, respectively. Means declined almost monotonically for the top four output quality sets, but in the lowest two sets of institutions there was a clear indication of quantity being used to compensate for reduced quality.

Fishe (1998) investigates the standards for promotion to full professor in the finance discipline. The publication records of 126 recently promoted US faculty are examined and the numbers of publications in seven top journals ${ }^{6}$ are compared across two groups of institutions with prestigious finance departments (the top 20 and the next 76). Faculty in top 20 departments place 1 out of 3 of their articles in the top three finance journals and 1 out of 2 in one of the top 6 journals. By contrast, faculty in the 21-96 top finance departments place 1 out of 6 of their articles in the top three finance journals and 1 out of 5 in one of the top 6 journals. Fishe explores the effect of extending the list of top finance journal to 14 by adding the next 11 highest impact journals identified by Borokhovich et al. (1995). He finds significant production substitutes among finance journals for faculty at the lower ranked institutions. ${ }^{7}$ The differences in relation to other finance and accounting journals were less pronounced.

The study by Swanson (2004) is of particular interest because it compares the publication quality norms that prevail in four business disciplines (accounting, finance, management and marketing) in the twenty-year period 1980-1999. Drawing on Ellison's $q-r$ theory (Ellison, 2002), he argues that differences exist in quality norms across disciplines and over time within a discipline. Ellison's $q$-r theory states that journal gatekeepers consider two aspects of a manuscript: the importance and interest of the main idea (q); and all other quality attributes, such as clear exposition and links to prior literature (r). Swanson finds that the mean proportion of faculty publishing in a major is found to be significantly lower in accounting compared to the other three disciplines. ${ }^{8}$ Over time, the number of articles in the top journals has declined, consistent with the upward drift in quality norms predicted by $q-r$ theory. 


\subsection{Gender effects}

Several studies have compared the publication records of male and female accounting faculty, with conflicting results. Studies that have not found significant differences include Fogarty, 2004; Streuly and Maranto, 1994; Dwyer, 1994; and Mann and Ormundson, 1991. In contrast, Rama et al. (1997) found that, in non-doctoral schools, females gaining promotion had more publications than males, while Buckless et al. (1998) report female adjunct professors required more impressive credentials than males to attain career advancement. All of these studies are based on the US academic community. A recent cross-discipline study set in Canada did find that it took females longer to gain promotion compared to males (Stewart and Ornstein, 2009). Potential explanations are that females devote more time to service activities and less time to research than males (Link et al., 2008) or characteristically seek promotion only when success is more likely compared to males.

\section{RESEARCH QUESTIONS}

A primary research objective of the present paper is to identify both the quantity (number of outputs) and quality of research outputs needed for promotion to professor in the UK in the accounting and finance discipline. In addition, analysis is undertaken to investigate, in the UK context, several moderating variables in relation to promotion benchmarks suggested by prior literature and anecdotal evidence: whether research expectations differ between universities with differing research emphasis (e.g., Glover et al., 2006); whether it is harder to obtain internal promotion compared to external promotion (Swanson, 2004); whether gender has an influence (e.g., Rama, et al., 1997); whether accounting and finance sub-disciplines have differing expectations (Swanson, 2004); any temporal changes in expectations (e.g., Brown et al., 2007); and whether there is evidence of a 'recency effect' in promotion requirements (e.g., Fishe, 1998). Each of these questions is now considered in turn.

For a variety of reasons, including issues of funding, the 'new' (post-1992) universities have in

general found the sustained development of research expertise and culture a major challenge. ${ }^{9}$ Thus, the 'binary divide' in large part remains in place, both in terms of overall university rankings ${ }^{10}$ and performance in the UK Research Assessment Exercise (RAE). ${ }^{11}$ The term 'pre-1992' is used throughout the present paper to describe the old, more research-focused, institutions with the term 'post-1992' being used for the new, less research-focused, institutions. Prior US research suggests that there are considerable differences in research output requirements for promotion depending on the research intensity of the accounting and finance department (e.g. Glover et al., 2006; Fishe, 1998). Recent UK research into the reward and recognition given to teaching in higher education indicates that the more research intensive institutions are believed to give low emphasis to teaching (Higher Education Academy, 2009: 52). Thus, a different emphasis on research might also be expected to be reflected in promotion to professor in the UK, leading to our first research question (RQ): 
RQ1: Are the number and quality of research outputs required for promotion to professor different in pre-1992 compared to post-1992 universities?

Second, certain features of the UK academic labour market encourage a perception by academic staff that gaining promotion within their home institutions (internal promotion) is more difficult than gaining promotion at another university (external promotion). There exists a thin market for good research academics in accounting and finance, partly due to the existence of more lucrative alternative employment opportunities in the fields of accounting and finance, which reduces the competition for external appointments. Also, internal promotions usually involve cross-discipline competition with academics whose discipline norms appear to result in a markedly higher number of outputs, which creates a very competitive internal market. Even within the business area disciplines, there appear to be significant differences in output quantities and qualities (Swanson, 2004). Additionally, promotees can engage in gaming, whereby success in securing an external promotion is used to lever the offer of an internal promotion. The net impact of these influences is explored in the second research question:

RQ2: Are the number and quality of research outputs required for promotion to professor different for internal and external promotions?

Third, the influence of gender in promotion contests has produced conflicting results in prior studies of the US academic market (see earlier). This issue is addressed in the third research question, which seeks to identify any differences between the pre-promotion output portfolios of male and female academics:

RQ3: Are the number and quality of research outputs required for promotion to professor different for promotions achieved by male and female academics?

Fourth, business-related disciplines have been shown to have different publication norms (Swanson, 2004). We investigate whether this finding extends to the accounting and finance sub-disciplines:

RQ4: Are the number and quality of research outputs required for promotion to professor different for promotions within the separate accounting and finance areas?

Fifth, there have been many changes in the UK academic environment over the last 30 years. The accounting and finance academic community, faced with huge increases in student numbers, has experienced a large increase in the number of academic staff, together with an increase in the proportion who are $\mathrm{PhD}$-qualified and a decline in the proportion who are professionally qualified (Brown et al., 2007). The research assessment environment has increased both the pressure to publish 
and the pressure to publish in designated top journals (RAE 2001; 2008; REF 2013; Moizer, 2009: 294), although there has also been a rise in the number of academic accounting journals (Zeff, 1996). The joint effect of these forces is a very thin market in accounting and finance faculty capable of producing research deemed of high quality. Other changes include the internationalisation of UK universities (both students and staff) and increased pressure to raise income in unregulated markets via taught postgraduate (TPG) programmes and the like. The latter potentially reduces the amount of time academics have available for research, yet increases the importance of reputation-enhancing research, of considerable influence in attracting high quality students into both TPG and PhD programmes. Prior US research suggests that the quantity and quality of journal outputs in pre-promotion publication portfolios has changed over time (Glover et al., 2006; Read et al., 1998). In the UK context it is, $a$ priori, unclear whether the changes in the academic environment have reduced the promotion benchmark (due to the thin market and high levels of competition to recruit/retain) or increased the promotion benchmark (due to the external pressure from government funding policy). Research question 5 addresses this critical issue of whether and how publication portfolios have changed:

RQ5: Has the number and quality of research outputs required for promotion to professor changed over time?

Sixth, prior research argues that both stock and flow of papers may be important in promotion decisions (Fishe, 1998). Staff who demonstrate a recent accelerated flow of papers may be promoted earlier based on the perceived quality of the flow (i.e., based on potential). In this scenario, recency is deemed to substitute for quantity. This may be especially likely in a thin labour market. This can be likened to the concept of student 'exit velocity' (performance in later modules) which influences a student's overall honours degree classification at some UK universities. Other staff may be promoted based primarily on attaining an acceptable stock of publications, demonstrating sustained research performance over a longer period of time. It may, of course, be necessary to have both a 'good' flow and 'good' stock of publications, indicating a complementary effect. Moreover, the relative importance of these two measures may vary both across time and across institutions. To investigate these issues, the main analysis (which is based on the 10 year pre-promotion publication portfolio, a stock measure), is repeated using a restricted most recent four year set, a flow measure, to investigate research question 6 :

RQ6: Are publication rates in the fours years leading to promotion to professor higher than publication rates in the ten year pre-promotion period? If so, does this reduce the number of outputs required for promotion?

There are four further potential determinants of pre-promotion output requirements which are investigated in the current study within a multivariate context. 
First, the research quality of the promoting institution is likely to be important (Glover et al., 2006; Fishe, 1998). This could operate at the institution level or at the 'department' ${ }^{12}$ level within the institution. For example, within pre-1992 institutions, both the Russell Group (20 universities) and the 1994 Group (18 universities) seek to differentiate themselves from other universities based on 'high quality' research. However, as observed in research assessment exercise results (RAE, 2001; 2008), there are often considerable differences in research quality across different disciplines within an institution, so discipline-level RAE ranking might also affect expectations for chair appointments.

RQ7: Does the research quality of the promoting department or institution have an impact on the number and quality of research outputs required for promotion to professor?

Second, while formal research assessment in the UK focuses primarily on quality, it is also possible that research output volume may have some impact on promotion decisions. This can reflexively impact upon the publishing strategy adopted by the individual, with $K$-strategists focussing on publications in designated top journals while $r$-strategists maximise quantity by targeting a large number of publications in lower-ranked journals (Faria, 2003, cited in Moizer, 2009). These arguments suggest a negative relationship between output volume and pre-promotion portfolio quality and this possibility is investigated in research question 8 :

RQ8: Does higher output volume substitute for output quality in pre-promotion portfolios?

Third, a US-based survey reports a perception that researchers may be given less than full credit for co-authored research and may need at least one sole-authored paper for tenure (Schinski et al., 1998). This suggests that a larger number of outputs may be required to compensate for co-authored research, potentially leading to a negative relationship between outputs and the number of sole-authored papers.

RQ9: Does the number of sole-authored papers reduce the number of outputs required for promotion?

Fourth, research reports prepared for professional accounting and other bodies are typical outputs following the receipt of research grants, and are often a requirement of the grant-awarding body. While such reports represent a relatively small proportion of research outputs $3.5 \%$ according to Beattie and Goodacre, 2004), they can provide evidence of a different dimension of research, namely practical relevance. Anecdotal evidence suggests that this dimension has been valued in the past by some institutions, and its importance is set to increase further in the UK, given the high proposed weight $(25 \%)$ attached to research 'impact' in the proposals for the next research assessment exercise 
(REF, 2009). The impact of research reports on promotion decisions forms the basis for the final research question.

RQ10: Does the number of research reports reduce the number of outputs required for promotion?

\section{METHODS}

\subsection{The data-source}

The biennial Register collects, via a survey of all institutions, details of the publications of accounting and finance faculty during consecutive periods of two calendar years. ${ }^{13}$ Knowledge that the register is widely used by academics provides strong incentives on both individuals and institutions to ensure completeness. Recent prior research using the Register acknowledges the need for significant tidying of the raw data, but after some testing also identifies the source as reasonably reliable (Beattie and Goodacre, 2004, 2006; Brown et al., 2007). Since the 1990 edition, the definition of 'publication' used excludes working papers, unpublished conference papers, in-house publications, private reports, and forthcoming publications. ${ }^{14}$

\subsection{The database}

The database was designed to support a rigorous analysis of publications at the community, institutional and individual levels, as well as social aspects of publishing activity such as promotion requirements, co-authorship behaviour and gender issues. To serve this purpose, a relational database, using Microsoft Access was constructed. This database extends that used by Beattie and Goodacre (2004) longitudinally by including twelve issues of the Register from 1984 (the first publication of the Register in bound form) to $2008 .^{15}$ The two principal data tables are the staff table and the publications table. The staff table included 7 fields capturing personal details, including aspects of background experience and training. The staff table has two supporting tables: institution and position. The publications table, linked via the author identifier to the staff table, captures authorship details as well as recording the type of publication. A fundamental distinction is made between serial and non-serial publications (Beattie and Ryan, 1991), in that the title of all serial publications is recorded but only the nature of non-serial publications (e.g. book chapter, professional report).

Promotion to professor was identified by comparing the academic 'position' field in the subsequent version of the Register. The publication records of promoted staff with pre-promotion records available for at least 10 years (5 biennial Registers) were extracted into an Excel spreadsheet for further manipulation and analysis. (A detailed explanation of the treatment of promotion timing is given in Appendix 1.) The choice of 10 years emerged judgmentally from balancing the need for a relatively complete publication history with the desire for a reasonable sample size, necessary for statistical analysis. For consistency, it was considered preferable to maintain a constant pre-promotion 
period for all professors. The 10 year period is also broadly consistent with arguments in prior US research (Fishe, 1998) suggesting a normal gestation period of 11 to 12 years for promotion to full professor.

The raw data then underwent detailed 'manual' checking for errors and for consistency in the precise naming of journals, necessary for matching journal outlets across academics. Finally, given the assumed importance of publication quality as well as number of publications, it was necessary to adopt a suitable quality proxy. The RAE (2008) subject overview report for Panel I makes it clear that, although the sub-panels did not use place of publication as an evaluative criterion, a correlation was observed:

"It is worthy of note that there was not a perfect correlation between the quality of a piece of work and its place of publication. Although much top-quality work was indeed published in what are generally regarded as leading journals, top-quality work could also be found in journals occupying a lower position in conventional rankings. Similarly, some of the work considered that had been published in so-called leading journals was thought to be of less than top quality."

While accepting that an agreed journal quality measure is elusive (and perhaps even illusory), for the purposes of the present paper it was necessary to make use of a proxy for publication quality. The need for an up-to-date measure with wide journal coverage encouraged the acceptance of the Association of Business Schools Journal Quality Guide (ABS, 2008). The second version of the Guide was published in May 2008, listing 125 'Accounting and Finance' Journals within a full list of 1,025 business journals, and uses a broadly similar scale to categorise journal quality to that used within RAE 2008 to categorise output quality. However, the descriptions used in the Guide (reproduced in the Table below) differ from RAE 2008, particularly in not using labels related to either 'international' or 'national' quality levels, or related to the criteria of 'originality', 'significance' or 'rigour'. The ABS Guide seems to be the most comprehensive, up-to-date and widely used listing currently available and has the extra advantage that it has been developed by UK academics specifically for the UK academic market. ${ }^{16}$

The publications listed in our extracted data from the Registers were matched to the journals listed in the ABS Guide and checked for consistency. This enabled a summary of journal output quality to be calculated and reported based on the starring criteria. Unclassified outputs (i.e., below $1 *$ level) and non-serial publications such as monographs, book chapters and professional reports, whose quality is indeterminate (based on the information available), are grouped together as 'non-ABS' outputs. 


\section{Specification of Journal Quality Standards applied in ABS (2008)}

\begin{tabular}{|c|c|c|}
\hline Quality Rating & Meaning & $\begin{array}{l}\text { No. and (\%) of } \\
\text { Journals in ABS } \\
\text { Guide }\end{array}$ \\
\hline $\begin{array}{l}4^{*} \\
\text { A top journal } \\
\text { in its field }\end{array}$ & $\begin{array}{l}\text { Publish the most original and best executed research } \\
\text { papers. These journals typically have high submission } \\
\text { and low acceptance rates. Top journals generally have } \\
\text { the highest citation impact factors within their field. A } \\
\text { small number of them rank by reputation and citation } \\
\text { amongst the world elite of academic journals. }\end{array}$ & $103(10.0 \%)$ \\
\hline $\begin{array}{l}* \\
\text { A highly regarded } \\
\text { journal in its field }\end{array}$ & $\begin{array}{l}\text { Publish original and well executed research papers. } \\
\text { Theses journals typically have good submission rates } \\
\text { and are very selective in what they publish. Papers are } \\
\text { heavily refereed. Highly regarded journals generally } \\
\text { have fair to good citation impact factors relative to } \\
\text { others in their field, although not all highly regarded } \\
\text { journals carry a citation impact factor. }\end{array}$ & $254(24.8 \%)$ \\
\hline $\begin{array}{l}2^{*} \\
\text { A well regarded } \\
\text { journal in its field }\end{array}$ & $\begin{array}{l}\text { Publish original research of an acceptable standard. } \\
\text { Papers are fully refereed according to accepted } \\
\text { standards and conventions. Well regarded journals } \\
\text { have modest citation impact factors or do not carry one } \\
\text { at all. }\end{array}$ & $406(39.6 \%)$ \\
\hline $\begin{array}{l}\text { 1* } \\
\text { A recognised } \\
\text { journal in its field }\end{array}$ & $\begin{array}{l}\text { These journals, in general, publish research of a modest } \\
\text { standard. Papers are refereed relatively lightly } \\
\text { according to accepted conventions. Few journals in this } \\
\text { category carry a citation impact factor. }\end{array}$ & $253(24.7 \%)$ \\
\hline $\begin{array}{l}\mathbf{N} \\
\text { A new or recently } \\
\text { published title }\end{array}$ & $\begin{array}{l}\text { These journals are recent entrants to the field and it is } \\
\text { therefore difficult to form a judgement as to overall } \\
\text { quality. They do not carry a citation impact factor. }\end{array}$ & $9(0.9 \%)$ \\
\hline
\end{tabular}

Several measures of pre-promotion outputs are analysed and reported: the number of papers published in ABS (2008) journals of particular quality (proxied by the $4^{*}$ to $1^{*}$ judgements with the ABS Guide); total number of ABS publications; total non-ABS publications; total number of outputs; weighted ABS score; number of $3 *+4 *$ papers; and, the number of $3 *+4 *$ papers as a percentage of total ABS papers. The weighted ABS score is equivalent to the single-number 'GPA' measure being used by many, post-RAE 2008, to facilitate the ranking of universities within an individual subject area (termed 'Unit of Assessment' (UoA) in RAE 2008), or in aggregate across all subject areas of a university. It is calculated as:

weighted $=\underline{(\text { No. of } 4 * \text { papers } \times 4)+(\text { No. of } 3 * \text { papers } \times 3)+(\text { No. of } 2 * \text { papers } \times 2)+(\text { No. of } 1 * \text { papers } \times 1)}$ ABS score Total no. of ABS papers

This score assumes that quality ratings represent an interval level of measurement, whereas only an ordinal level exists. This is, therefore, a crude measure of the overall quality of the refereed journal papers within a particular professor's pre-promotion portfolio. 
Initially, research questions are addressed using univariate analysis of pre-promotion outputs across the several dimensions outlined in section 3 above. While this is useful, particularly in a descriptive sense for benchmarking performance, the univariate analysis requires a ceteris paribus assumption, which is unlikely to be tenable. So the second stage involves a multivariate analysis using OLS regression, seeking to take all factors into account simultaneously and to include the other potential explanatory factors outlined at the end of section 3. This seeks to 'explain' the different characteristics of observed pre-promotion publication portfolios in terms of attributes of the promotee and the promoting institution and/or department. It is beyond the scope of the present study to investigate what determines the gaining of promotion to professor per se; i.e., we do not consider why some academics obtain promotion to a chair and some do not. This would require a different research design, including information on those who do not gain promotion.

Two measures are adopted as dependent variables in the analysis. The total number of ABS (2008) publications is selected as a proxy for the volume of research meeting a particular quality threshold. The total number of outputs is selected as a more complete measure which fully captures research volume. Both were measured over the 10 year period 'prior' to promotion. ${ }^{17}$ Dummy variables $(=1)$ were used to identify the key dimensions of: post-1992 institution; internal promotion; female academic; working in the finance sub-discipline or at the finance/accounting interface; and time period of promotion. For the latter, the most recent period 2006-7 was treated as the base period for comparison, so the dummy for this period is excluded from the regressions. To assess the impact of any 'exit velocity' (or 'recency effect'), the total number of ABS journal publications and total outputs measured over the four-year period immediately prior to promotion were used, matched in the regressions with the equivalent dependent variable. An indicator of exit velocity impact would be the finding of a negative relationship here; i.e., if a promotee has a larger number of recent outputs they might need a commensurately smaller number of total outputs as a result.

To incorporate the four additional factors outlined at the end of section 3, further proxies/variables are needed. As proxies for institution/department research quality, separate dummy variables were used to identify the promoting institution being a member of the Russell Group of 20 universities or of the 19 universities belonging to the 1994 Group. ${ }^{18}$ The RAE 2008 research assessment can provide a potentially useful indicator of discipline-based research quality. Given that some institutions made submissions to both the "Business and Management" (B\&M) and the "Accounting and Finance" (A\&F) panels, for consistency across institutions an aggregate RAE 2008 score was calculated. ${ }^{19}$ This was measured as the average of the profile GPA scores received for the submissions to B\&M and A\&F panels, weighted by the number of staff submitted to each panel. ${ }^{20}$

The proxy adopted for 'quantity', within a 'quality'-based regression, was the total number of outputs over the 10 year period after deduction of the number of ABS journal publications and of research 
reports for professional accounting and other bodies. The latter deduction was necessary to avoid overlap with the measure used to assess the impact of research reports. Sole-authorship was measured by the number of ABS publications for which the promotee was the sole author. ${ }^{21}$ The final variable included was the number of research reports.

\section{RESULTS}

\subsection{Sample characteristics}

A cross-tabulation summary of the characteristics of the 140 chair promotions in the sample is provided in Table $1 .^{22}$ Overall, 105 (75\%) were to pre-1992 institutions and 35 to the less research intensive post-1992 institutions (Panel A). ${ }^{23}$ In total, promotions to 64 different institutions are represented in the data (see Appendix 2 for the complete list). The last Register used in the study listed a total of 109 institutions at the end of 2007, with 56 post-1992/Irish and 53 pre-1992 institutions. Promotions in the present sample were to 25 post-1992 and 39 pre-1992 institutions reflecting $45 \%$ and 74\% of the Register 'institution populations', respectively. The larger percentage for pre-1992 institutions reflects the greater number of professors in these more research-intensive environments. Inspection of Appendix 2 suggests that some of the larger London-based institutions may be underrepresented in the sample, perhaps reflecting a different approach to promotions and rewards. Overall, subject to this proviso, the sample of promoted professors seems likely to be broadly representative of the population, especially from the perspective of UK academics.

\section{[Table 1 about here]}

Association tests (Chi-square or Fisher's Exact test) were conducted to detect any significant associations between promotees' characteristics. Table 1 (Panel A) provides a cross-tabulation of promotions to pre- and post-1992 institutions over the time period, with no real pattern discernible (Fisher's Exact test, $\mathrm{p}=0.388$ ). Panel B shows that almost twice as many of the promotions were internal (64\%) rather than external (i.e., to a different institution), which may indicate a willingness of institutions to seek to retain good research staff in the supply-weak market and research assessment environment of the UK; again there is no discernible time pattern here (Fisher's Exact test, $\mathrm{p}=0.528$ ). Panel C indicates that $81 \%$ (19\%) of the sample promoted academics were male (female), reflecting the general gender imbalance in senior positions across many sectors of the economy (e.g. Higgs, 2003; ACCA, 2007). There is fairly weak evidence here (Fisher's Exact test, $p=0.081$ ) of a 'positive' time dimension to the imbalance, with some indication of an increasing number and proportion of chair promotions for females. The Pearson correlation between proportion of female promotions and time is also a significantly positive $0.86(\mathrm{p}=0.007)$. It will be interesting to see whether this trend will be sustained in the future. There is also weak evidence of an increased proportion of promotions in the Finance area (Panel D). However, there does not seem to be any association between gender and pre- 
/post-1992 institutions (Panel E) or internal/external promotions (Panel F). Finally, Panel G provides strong evidence that the split between accounting and finance professors is different in pre- and post1992 institutions; approximately 1/3 of promotions are in finance in pre-1992 but less than 1/10 in post-1992 institutions.

\subsection{Univariate results}

\subsubsection{Overall output distributions}

Table 2 (Panel A) presents distributions of outputs in the 10 years prior to promotion for the 140 promoted professors, analysed initially by the number and quality of journal articles using the Association of Business Schools Academic Journal Quality Guide (ABS, 2008) as a proxy for output quality. The overall mean (median) number of ABS journal articles was 8.6 (8.0) with 5.2 (5.0) at the $3 * / 4 *$ quality level. With the addition of 11.8 (10.0) non-ABS outputs, this gives a total of 20.4 (17.5) outputs. ${ }^{24}$ The similarity between means and medians suggests that there is no great outlier distortion of the mean. There is clearly a wide variation in pre-promotion output levels with the number of ABS outputs ranging between 0 and 21, and total outputs between 3 and 73. The lower levels here presumably indicate that research is not always the most important attribute that UK universities seek to reward via promotion to professor. While there are unlikely to be any formally designated nonresearch chairs, it is possible that a very small number may have been de facto. ${ }^{25}$

[Table 2 about here]

Individuals and promotion committees may wish to have an idea about minimum acceptable levels of research output for promotion to professor. To get a rough idea of the minimum output levels that would normally be expected, in the absence of unusual non-research circumstances, the $16.5^{\text {th }}$ percentile measure is reported; this is similar to the mean of the lower tercile reported by Glover $e t$ al. (2006). This indicates that a typical minimum output level might be 1.9 journal papers at $3 * / 4 *$ level, within 4 ABS articles and 10 total outputs. However, this needs careful interpretation in the context of the relative research intensity of the university, as discussed in the next section.

\subsubsection{Analysis based on institution research intensity}

Panel B of Table 2 reports the same measures based on promotions to more research intensive (pre1992) and less research intensive (post-1992) university groupings, respectively. This panel shows statistically significant differences between the mean levels of outputs required for promotion in the two groupings. As expected for greater research-focused institutions, pre-1992 universities have higher research-based promotion thresholds. For example, the mean number of $3 * / 4 *$ level outputs is higher [6.2 versus 2.5], within a higher number of ABS papers [9.4 versus 5.9] showing also as a higher weighted ABS score [2.62 versus 2.11]. Typical minimum output levels (16.5 ${ }^{\text {th }}$ percentile) are also higher for pre-1992 institutions: 2 journal papers at $3 * / 4 *$ level, within 4 ABS articles and 10.2 
total outputs compared with 0,2 and 9.2 respectively for post-1992 institutions. However, while the number of higher quality outputs is typically greater for pre-1992, the number of non-ABS outputs is lower on average (mean $=11.4$ versus 13.1 ) leading to a different number of total outputs (20.8 versus 19.0), though neither difference is statistically significant. Overall, the quality of outputs is a more important criterion for promotion to professor in the more research intensive universities (RQ1).

\subsubsection{Analysis of internal and external promotions}

Comparisons of outputs for promotion within an institution (internal) and for promotion to professor at another university (external) are provided in Panel A of Table 3. These show that there are slightly higher thresholds for internal promotion. For example, the mean number of ABS outputs is 9.1 for internal compared with 7.6 for external promotions, with broadly similar differences on other measures. However, the differences are not statistically significant, implying no real evidence of a higher threshold to obtain promotion within an individual's own university (RQ2). It should, however, be recognised that internal promotions include cases where an external offer was made and the home institution successfully made a counter offer. This may explain, at least partly, why no significant differences were found. It may still be the case that internal promotion is more difficult in the absence of an external offer.

\subsubsection{Analysis of gender differences in promotions}

Table 3 (Panel B) splits the promotion statistics by gender. The number of outputs required for promotion for males and females is very similar. The mean (median) number of ABS papers for males is $8.5(8.0)$ and for females $8.6(9.0)$, with high quality $(3 * / 4 *)$ output numbers slightly higher for males at 5.4 (5.0) compared with 4.6 (5.0); however, none of the differences is statistically significant. Overall there is no evidence of any gender effect, i.e., there is no evidence that it is harder for females to get promotion, although the sample of female promotees is small $(n=27)$ and this could affect the power of the test. To examine whether gender effects might exist at the more research intensive institutions, Panel B of Table 3 was recalculated based only on pre-1992 institutions. The (unreported) results show almost identical numbers of pre-promotion outputs for males and females. Mean ABS outputs are 9.4 for males and 9.5 for females and mean $3 * / 4 *$ outputs are 6.3 for males and 5.4 for females. Thus, even in research intensive universities, there is no evidence of any gender difference in outputs required for promotion (RQ3).

[Table 3 about here]

\subsubsection{Analysis of promotions within accounting and finance sub-disciplines}

Categorisation of promotions into accounting, finance and accounting/finance (the latter category comprises academics at the interface between the two sub-disciplines) was undertaken separately by two researchers based on information available in the Registers or occasionally on an individual's web pages. ${ }^{26}$ This categorisation resulted in 101, 33 and 6 promotions within accounting, finance and 
accounting/finance, respectively. Panel $\mathrm{C}$ of Table 3 shows that promotions in accounting typically have slightly lower mean levels of ABS journal outputs (8.2 versus 9.3/9.5) and these of slightly lower mean quality (total $3 * / 4 *$ outputs of 4.9 versus $6.0 / 6.1$ ), but the differences between accounting and finance are not statistically significant. By contrast, accounting promotees have a statistically significant larger mean number of non-ABS journal publications (14.0 versus 5.1/6.3) and, therefore, also of total outputs (22.2 versus 14.4/15.8). Overall, there is no evidence that the key ABS journal requirements differ between the accounting and finance sub-disciplines (RQ4). However, it is important to recognise that only three of the 39 finance and accounting/finance sub-sample were promoted to post-1992 institutions, and this could affect the power of the test.

\subsubsection{Time series analysis of promotion thresholds}

To assess the effect of changes in the academic environment, the time series of numbers of promotions and research output promotion thresholds are presented in Panel D of Table 3. Each row summarises the promotions that took place within a particular two-year Register period; annual analysis is not possible as the precise promotion dates are not available within the data sources. While the relatively small number of time periods limits the analysis, there does not seem to be a very clear general trend in promotion thresholds over the 16 year period; however, there are some interesting patterns. For total ABS journal outputs, the 1992-3 threshold seems to be relatively low (mean $=4.1$ ) rising to one peak in 1996-7 $($ mean $=11.1)$, another in 2000-1 $($ mean $=10.2)$ and possibly a third in 2006-7 (mean = 10.7). The pattern for ABS $2 *$ journal outputs is also similar. There is certainly no evidence of any time-related downward trend in the numbers of quality outputs (proxied by ABS journals) required for promotion. By contrast, there does appear to be a fairly clear downward trend in total non-ABS outputs (Pearson correlation coefficient $=-0.34 ; p=0.000$ ). Oneway ANOVA confirms that there are significant differences in means over time for these three variables, and post-hoc significance tests broadly confirm the above observations (see Note 6 to Table 3).

It could perhaps be argued that the pattern for total ABS journal publications matches the end of the three RAE cycles (1992-6, 1997-2000 and 2001-7), though the small number of completed cycles and number of promotions within each period (12-20) warrant cautious interpretation. One rationalisation for the end-of-cycle peaks would be that the RAE focuses universities' attention on researchers with high quality outputs. One mechanism to encourage retention of such researchers is promotion to professor; indeed, there is some evidence that a larger proportion of promotions were internal during the three end-of-cycle periods: $74 \%$ compared with $60 \%$ in other periods, on average.

The downward trend in non-ABS publications is also consistent with an RAE effect. The RAEs have required research-active staff to 'submit' their four 'best' publications for evaluation. This RAE emphasis on a small number of 'high quality' publications, together with research grant income and $\mathrm{PhD}$ student numbers, may have encouraged a greater researcher focus on output quality rather than 
quantity. The peer-review process for journal publications together with the various journal ranking schemes (such as ABS) also provide a rough indication of output quality. This potentially reduces (but does not eliminate) the uncertainty related to how the four submissions will be evaluated by the RAE Panels. In turn, this would encourage a lower emphasis on non-journal outputs (such as book chapters and reports for professional bodies) and papers in non-ABS journals, as observed. Further, the increasing number of promotions in the finance sub-discipline, typically having lower numbers on non-ABS outputs, has likely contributed to the downward trend in non-ABS publications.

Overall, assuming that journal publication standards have not changed, there is no evidence to support the contention of 'falling standards' in UK promotions. However, there do appear to have been changes in pre-promotion portfolios over time, conjectured to be related to the RAE regime in the UK (RQ5).

Finally, Levene's test (for the homogeneity of variances) was carried out to assess whether there are any significant time-related differences in the variances of the number of ABS journal papers and the total number of publication in pre-promotion portfolios. Neither of these two benchmarks showed significant differences in the variances over time. Similarly there were no observable trends in variances (i.e., in simple regressions of benchmark variances against time the slope coefficients were insignificant). Thus, there is no evidence here of increasing institutional isomorphism (Wedlin, 2006; 2007) or of a homogenising tendency (Churchman, 2002).

\subsubsection{Investigation of 'exit velocity' in promotion portfolios}

To investigate whether there is evidence of 'exit velocity' in pre-promotion publication portfolios, the original analysis (reported in Table 2) was repeated based on a restricted data set of outputs in the 4 years immediately preceding promotion. ${ }^{27}$ Results from this further analysis are reported in Table 4.

[Table 4 about here]

This shows that the mean (median) number of ABS publications in the 4 year 'pre-promotion' period was $4.8(5.0)$ with $2.9(3.0) 3 * / 4 *$ publications, within a total of 10.1 (9.0) outputs. If there is 'exit velocity', the publication rate would be expected to be higher in the 4 year than in the 10 year period; i.e., the mean of the 4 year period would be greater than $4 / 10$ ths of the 10 year period. This is tested using a 1 tail t-test and significance is reported at the foot of the table.

There is strong evidence for 'exit velocity' (or a 'recency effect') in six of the summary statistics. In particular, in answering RQ6, the publication rate for the total number of ABS papers, the number of high quality papers $(3 * / 4 *)$ and the overall number of outputs are all significantly higher (at the $1 \%$ level). For example, the mean number of ABS papers over 4 years (4.8) is significantly higher than the 
expected 3.4 (40\% of 8.6 per Table 2), based on the 10 year output level. This 'recency effect' is consistent with academics seeking promotion after a recent period of relatively high level and quality of research performance; based on our sample of successfully promoted academics, this recent performance seems to carry some weight in promotion panel decisions.

\subsection{Multivariate analysis}

A difficulty in interpreting the univariate results is the necessary ceteris paribus assumption. Results from the multivariate analysis, which allows for the competing alternative explanations for univariate observations, are provided in Table 5. Three OLS regression models are presented, each possessing good explanatory power with adjusted $\mathrm{R}^{2}$ over $70 \%$. Model 1 has the total number of ABS journal papers as dependent variable and covers the full sample, except for the three Irish promotions whose institutions are not involved in the UK research assessment exercises (so lack data for the RAE 2008 score variable). There are several interesting observations. First, this model provides no evidence that the number of ABS papers required for promotion is lower in post-1992 institutions once other potential explanatory factors are taken into account, in contrast with the univariate analysis (RQ1). Second, and now consistent with univariate results, internal promotions (RQ2), gender (RQ3) and accounting or finance sub-discipline (RQ4) do not seem to affect pre-promotion portfolios of quality journal outputs.

Third, Model 1 also shows that the number of ABS publications required was significantly lower in four (perhaps 5) earlier time periods than in the most recent base period 2006-7. This does suggest that promotion requirements may have increased over time (probably from 2000 onwards), particularly in line with the increasing importance of and focus on research assessment in the UK (RQ5). Fourth, there is a very strong significantly positive association between output numbers in the 4-year and 10year pre-promotion periods. While the univariate analysis provides evidence of 'exit velocity' in publication rates, this does not seem to reduce the number of ABS publications required for promotion, i.e. the impact of 'exit velocity' seems, at best, to be relatively small (RQ6). Fifth, perhaps surprisingly, the research quality of the institution (proxied by inclusion in the Russell or 1994 Groups) does not seem to be significant and neither does the 'department' ranking in the most research assessment exercise (RAE 2008 score) (RQ7). Finally, the 'quantity' proxy (non-ABS outputs) is weakly significantly positive, suggesting that promotees with larger numbers of ABS journal publications also typically have larger numbers of other publications, i.e., they are generally more productive. This is inconsistent with the logic of quantity substituting for quality (RQ8). Similarly, both sole-authorship (5\% level) and the number of research reports (not significant) are positively related to ABS publications, providing little evidence that sole-authorship (RQ9) or research reports (RQ10) have a significant substitution effect in promotion decisions. This does not necessarily mean that they are considered as unimportant by interview panels, however. 
Tests for collinearity suggest that it is not a major issue in the regression models. The bivariate correlation matrix shows just one correlation above 0.5; the Pearson correlation between post-1992 and RAE 2008 score is -0.72 . The largest variance inflation factors in the three models are 3.0, 2.0 and 2.9 respectively, well below the suggested cut-off of 10 . Similarly the condition index, based on maximum and minimum eigenvalues from Principal Components Analysis of the explanatory variables, is between 4.6 and 4.8 for the three models, once again way below the suggested cut-off of 10. However, the relatively high post-1992/RAE 2008 score correlation does suggest caution in interpreting coefficients on either variable, which may be proxying for the other.

In light of the above, further investigations based only on the more research intensive pre-1992 subsample of promotions are carried out in Model 2, again with the number of ABS journal papers as dependent variable; interpretation of the RAE 2008 score coefficient should not be affected by any hint of collinearity. Very similar results are obtained. The coefficient on RAE 2008 score is positive, but again not significant (RQ7). One difference is that Model 2 provides weak evidence (10\% level) that internal promotion may require a higher number of ABS journal articles for promotion at pre1992 institutions (RQ2).

\section{[Table 5 about here]}

Model 3 repeats the Model 1 analysis across all institutions but is based on the broader 'quantity' measure of total number of publications of any type. The results are generally similar to Model 1, but three factors now emerge as statistically significant (at the $5 \%$ or $1 \%$ level). First, it appears that internal promotions may require a higher numbers of total outputs than external promotions, controlling for other effects (RQ2). Second, there is strong evidence of a lower total number of outputs for promotions in the finance area, consistent with the univariate analysis (RQ4). Finally, there is evidence that more outputs are typical in pre-promotion portfolios for promotions at the '1994 Group' of institutions (RQ7).

\subsection{Specific journals included in professor promotion portfolios}

Given prior research reporting the wide diversity of outlets accessed by the accounting and finance community (Beattie and Goodacre, 2004), it is interesting to consider the publication outlets of promoted staff. Table 6 lists the most 'popular' journal outlets within the pre-promotion portfolios (those with $\geq 10$ papers), together with the subject grouping adopted in the quality source (ABS, 2008). Perhaps unsurprisingly, this table shows a high degree of correspondence with the distribution reported for the entire community in Beattie and Goodacre (2004). Journal of Business Finance \& Accounting, Accounting and Business Research, British Accounting Review, Critical Perspectives on Accounting, Accounting, Auditing \& Accountability Journal, and Accounting Education: An International Journal are the most frequent journals, each with over 50 papers; the first four have a $3 *$ 
rating in ABS (2008) and the latter is 2*. The 27 most popular journals listed account for $65 \%$ of the total 1,199 ABS journal papers in the promotion portfolios.

[Table 6 about here]

Table 7 summarises two aspects of the pre-promotion papers. First, while a large proportion $(69.1 \%)$ of the papers were published in 79 different journals within the Accounting and Finance (A\&F) subject area (as defined in ABS (2008)), the remainder (30.9\%) were published in a total of 127 'other discipline' journals. This is consistent with the observation made elsewhere that accounting and finance research both draws upon and contributes to literature in other disciplines (e.g. Beattie and Davie, 2006). The most popular 'other discipline' was Management Development and Education in which ABS (2008) classified the popular Accounting Education: An International Journal.

\section{[Table 7 about here]}

Second, the final three columns of Table 7 highlight the very small number of $4^{*}$ journals and papers therein included in the pre-promotion portfolios. Professors' pre-promotion portfolios included a total of just 70 papers (5.8\% of total ABS papers) published in 9 journals in the A\&F subject area, rated as $4 *$ within ABS (2008). 42 of these papers were published in just one of the $4 *$ journals (Accounting, Organizations and Society) with a further 28 papers in 8 other A\&F $4 *$ journals. All of these eight journals are edited and published in the US and it is well-established that UK academics find it difficult to publish in such journals (Jones and Roberts, 2005). Further, Beattie and Davie (2006) document the existence of geographically-based competing research elites (one US and one non-US) based on methodological differences. The scarcity of $4^{*}$ A\&F journals outside the US, combined with the methodological specialism of Accounting, Organizations and Society, represent constraints that promotion panels (and aspiring promotees) have to operate within. An additional 21 papers were published in 15 non-A\&F subject area $4 *$ journals making 91 papers in total (7.6\% of total ABS papers). Further detailed analysis shows that there were actually zero $4^{*}$ publications in the prepromotion portfolios of 65\% (91\%) of promotions at pre-1992 (post-1992) institutions, i.e., overall, only 40 out of the 140 promotions (29\%) had any $4 *$ publications. Two controversial and mutually non-exclusive explanations can be put forward for the small number of $4 *$ publications. It may be that the 4* standard for A\&F journals applied within ABS (2008) is relatively 'harsh', ${ }^{28}$ or perhaps the standard of scholarship of professors in A\&F is relatively low. A third argument might be that promotions to professor are obtained relatively early in the A\&F discipline, due to the thinness of the labour market, with professors producing higher quality work after they achieve promotion; future research can assess the empirical validity of this argument. 


\subsection{Comparison with Glover et al.'s (2006) study of promotions in the US}

In their US study, Glover et al. (2006) identify a restrictive set of journals to represent output quality based on prior journal quality surveys. They group journals in a hierarchy as Top 3 Accounting and Through Top Business (top business journals in other disciplines but including the 3 accounting journals), then Through Top 6 Accounting (i.e. an extra 3 accounting journals added to the full business list), Through Top 15 Accounting and Through Top 25 Accounting. The latter full list includes 25 accounting plus 35 business journals making 60 journals in total. This contrasts with our approach which potentially includes any of the 1,025 journals listed in ABS (2008) including the 125 journals listed in the Accounting and Finance subject group.

To enable a comparison with the Glover et al. study, Table 8 lists the journals common to both studies; i.e. journals represented in UK pre-promotion portfolios that are also included in the list of 60 journals in Glover et al. (2006). It also shows the ABS quality rating of each journal, the numbers of papers published therein by the UK promoted academics, and the Glover et al. categorisation.

\section{[Table 8 about here]}

Overall, 269 (22\%) out of the total of 1,199 ABS journal papers were published in Glover et al. journals, with accumulating totals as shown in the table. Only 3 journals in the Glover et al. list are significantly represented in the UK pre-promotion portfolios: Accounting, Organizations and Society, Journal of Business Finance \& Accounting and Accounting and Business Research. Thus, there is a very restricted crossover in the publication journal set between the US and the UK, as previously highlighted in Jones and Roberts (2005). This reinforces the view of Lukka and Kasanen (1996), supported by empirical evidence by Beattie and Davie (2006), that accounting remains a local discipline, with a US elite distinguishable from an emerging non-US elite. Consequently, the reported Glover et al. (2006) promotion 'benchmarks' are of very little help or use in the UK environment; also, further comparisons between the two sets of results are of little benefit.

\section{SUMMARY AND CONCLUSIONS}

The study establishes promotion publication benchmarks in relation to the quantity, quality and nature of research outputs associated with promotion to the senior rank of professor in the UK. This is achieved using the publication records of academic staff in the accounting and finance community promoted to professor over 1992-2007, as detailed in the biennial British Accounting Review Research Registers. Prior literature on promotion hurdles, and anecdotal evidence from the UK setting, suggest a range of factors related to these benchmarks. Statistical analysis is used to examine these relationships. 
On average, approximately 9 papers in ABS (2008)-listed journals, with 5 at the $3 * / 4 *$ level in a portfolio of 20 outputs are required for promotion. However, the distributions show that there is a wide variation in implied promotion requirements. Perhaps unsurprisingly, there is evidence consistent with academics seeking promotion after a recent period of relatively high level and quality of research performance. Multivariate analysis provides evidence that publication requirements in terms of ABS ranked journal papers have increased over time, an effect attributed to the dominant impact of the government research assessment exercises. To some, this could be seen as evidence of an increased emphasis on research, presumably a desired outcome from a government or managerial perspective. To others, it could be seen as the outcome of increasing commodification and managerialism, with potential consequences of focus on short-term, less risky, less practically-relevant research and reduced focus on teaching, service and collegiality (Puxty et al., 1994; Humphrey et al., 1995; Willmott, 1995; Parker et al., 1998).

There is no evidence that requirements differ for: internal versus external promotion, male versus female candidates; or accounting versus finance professors (though finance professors do have less non-ABS publications in their pre-promotion portfolios). The research intensity of institution peer group is also unrelated to the ASB publication benchmark, a finding which is inconsistent with US research and research from other disciplines that finds the promotion hurdle to be higher at more research-intensive institutions (Glover et al., 2006; Seggie and Griffith, 2009). The government research ranking of the unit is also unrelated. There is no evidence of a substitution effect in relation to increased recent publication history, quantity of non-ABS outputs or sole-authorship, all of which show a significant complementary effect. The restricted crossover in the pre-promotion publication journal set between the US and the UK, is interpreted in terms of the greater paradigmatic diversity permitted in the UK and consistent with prior research (Lukka and Kasanen, 1996; Beattie and Davie, 2006). Finally, there is no evidence in promotion requirements of increasing institutional isomorphism (Wedlin, 2006; 2007) or of a homogenising tendency (Churchman, 2002).

The promotion publication benchmarks provided in this study can assist in a variety of decision settings (e.g., recruitment, promotion, cross-disciplinary comparisons and resource allocation). The statistical analysis tests, in a new and different setting from the US, whether a range of factors influence the promotion hurdle. Finally, the combined evidence offers critical insight into current policy debates concerning the aging demographic profile of accounting faculty, the management of academic labour and the Research Excellence Framework (REF, 2009). Crucially, it is found that the number of ABS journal articles in the pre-promotion portfolio has increased over the period, consistent with the increasing impact of the research assessment exercises on the behaviour of individuals and institutions. 
As with all studies, the present study has a number of limitations. First, there is inbuilt selection bias, in that only those who have successfully achieved promotion to professor feature within the study (i.e. no comparison is possible with the publication portfolios of those who have been unsuccessful in their promotion application). Second, the proxy used for journal publication quality necessarily involves an element of subjectivity and is less than ideal. Finally, while the results provide an indication of the research output standards required for promotion across a range of universities, this activity only represents a partial picture (albeit a major part) of the characteristics required for promotion. 


\section{ENDNOTES}

${ }^{1}$ Of course, by using quantified proxies in this paper, we arguably participate in the commodification process.
We justify this with reference to the potential benefits that arise from improving our understanding of how this
commodification has impacted promotion criteria.

${ }^{2}$ US survey evidence has consistently shown that faculty members and evaluators weight research more heavily than either teaching or service in promotion and tenure decisions. See, for example, Street and Baril (1994) for the accounting discipline and Tripathy and Ganesh (1996) for the finance discipline. Street and Baril (1994) survey deans and accounting department heads at US AACSB-accredited universities to establish the relative importance assigned to 39 scholarly accomplishments in promotion and tenure decisions. They find that publications, external recognition and funding count most across all institutions. Academic publications and external recognition dominate at doctoral-granting institutions, while practitioner publications, pedagogical publications and teaching are more highly weighted at universities with a more comprehensive mission.

${ }^{3}$ Studies also exist based on: library journal holdings (market test studies); the internet download frequency of working papers; inferences about individual quality choices based on the subset of outputs selected for submission to the RAE from the set available; and dissertation citation analysis. The number of journals ranked varies, although it has tended to increase over time in line with the number of journals in existence.

${ }^{4}$ Seggie and Griffith (2009) apply the economic concept of imperfect substitution and the associated assignment problem to the academic promotion decision, while Baker et al. (2006) apply tournament theory to the internal promotion competition in law firms.

5 Brown et al. (2007: 126) note that, over the last 10 years, only six articles have been published by UK academics in the three accounting journals which are often recognised as top publications: The Accounting Review (TAR), Journal of Accounting Research (JAR) and Journal of Accounting and Economics (JAE).

${ }^{6}$ Three finance journals (Journal of Finance, Journal of Financial Economics, Review of Financial Studies), Journal of Business and three economics journals (Journal of Political Economy, American Economic Review and Econometrica).

${ }^{7}$ They publish, on average, $20 \%$ of their articles in the top 4 finance journals and $32 \%$ in the next top 11 finance journals, compared to faculty at the higher ranked institutions who publish, on average, $42 \%$ of their articles in the top 4 finance journals and $12 \%$ in the next top 11 finance journals.

${ }^{8} 0.06$ for accounting, 0.11 for finance and management and 0.13 for marketing.

${ }^{9}$ Casual empiricism and anecdote suggest that senior managers at the post-1992 institutions bemoan the fact that home-grown research talent tend to move on to the pre-1992 universities where teaching loads are often lower and the institutional reputation is higher.

${ }^{10}$ Commenting on the Independent on Sunday's 'The Complete University Guide 2008', Andy Sharman commented: "The post-1992 crop of universities once more failed to break into the top 50 and the binary divide that has separated them from the old universities remains intact. Only Nottingham Trent and the University of Hertfordshire managed to cross the traditional line, beating Bangor, which was the lowest placed old university" (Sharman, 2008).

${ }^{11}$ For example in RAE 2008, accounting and finance academics were typically submitted within either the 'Accounting and Finance' (A\&F) or the 'Business and Management' (B\&M) units of assessment (UoA). In a ranking of institutions based on the simple grade point average (weighted quality score), just 1 (out of 7) and 1 (out of 45) post-1992 university appeared in the top half of the rankings of these UoAs, respectively. By contrast, in the bottom half of the rankings they had 5 (out of 7) and 38 (out of 45), respectively. The mean GPA score and number of research active staff submitted by post-1992 institutions were also significantly lower than pre1992 institutions: for the A\&F UoA, mean GPA = 1.90 versus 2.43; mean number of FTE research active staff = 6.0 versus 15.5; the equivalent figures for the B\&M UoA were: 1.87 versus 2.61 and 19.0 versus 50.9.

${ }^{12}$ In recent years, academics within the accounting and finance discipline are more likely to form part of a larger business or management school grouping than existing as a fully independent department, though there are notable exceptions. In some institutions, it is possible that the research quality of this larger grouping is likely to exert a significant influence. 
${ }^{13}$ To be included, individuals must meet one or more of the following criteria: be located in an accounting and finance department; have a primary commitment to teaching and research in accounting and finance; be a teacher who does the bulk of their teaching on accounting and finance degree courses; or be a researcher who publishes in accounting and finance journals.

${ }^{14}$ Consequently, to ensure comparability, it was necessary to remove a small number of working papers from the pre-promotion publication records of some promotions occurring in the earlier years of the study.

15 The first (unbound) edition of the Register was published as the AUTA: News Directory in 1982 (Brown et al., 2007 ) but, given its extremely patchy publication coverage, was not used in constructing the source database for the current study.

16 The Association of Business Schools published a third edition of its journal rankings guide in 2009 (ABS, 2009). Investigation of the changes in journal rankings between versions 2 and 3 identified a very small number relevant to the present study. In particular, there are 12 changes which could potentially affect the results: 6 journals went up and 6 went down by one grade, affecting 30 out of the total of 1,006 ABS listed journal papers in our analysis. Given this negligible effect, we have continued with the ABS (2008) rankings.

17 Two other measures were used in some regressions as a check for robustness: the number of $3^{*}$ plus $4^{*}$ publications and the weighted average ABS score. The broadly similar results are not reported here.

18 Further information, including a list of member institutions is available on their respective websites: http://www.russellgroup.ac.uk/ and http://www.1994group.ac.uk/. The 1994 Group expanded to 19 institutions on 1 August 2009 when the Institute of Education, University of London joined the group.

${ }^{19}$ Unfortunately, a separate RAE quality profile for the accounting and finance discipline is only available for a relatively small number of groups (14 in total). Members of the accounting and finance groups were typically submitted either to the "Business and Management" (B\&M) or the "Accounting and Finance" (A\&F) panel, depending on whether accounting and finance was considered as part of an overall business school submission. If to the former panel, then accounting and finance is subsumed in the overall B\&M profile for the institution. However, this will provide an overall indicator of research quality within the broad business area which can be used as a rough proxy for accounting and finance.

${ }^{20}$ The usefulness of this proxy for research quality in the present study requires the additional assumption that quality is relatively stable over time. Anecdotally, while there have been some changes over the timeframe studied here, these appear to be relatively small in contrast to a broadly stable institutional 'pecking order' in accounting and finance research.

${ }^{21}$ An alternative measure, the number of sole-authored $3 *$ plus $4 *$ ABS publications was also used, with similar (unreported) results.

${ }^{22}$ The sample represents $65 \%$ of the population of 217 promotions to professor that are identifiable from the Registers during the sample period. The remaining 77 promoted staff did not have the required minimum of 10 years pre-promotion records available within the Registers.

${ }^{23}$ While a similar split is not applicable within the Irish context, the 3 promotions to Irish institutions are included within the post-1992 subsample. This allocation is intended to reflect a perception that there may be less research pressure in Irish universities (e.g. there are no formal government-sponsored research assessments in contrast with the UK). Exclusion of these 3 promotions has a negligible effect on the reported results and analysis.

${ }^{24}$ On average, pre-promotion portfolios contain 5.9 non-journal types of output, particularly book chapters (2.6), books (1.1) and research reports for professional accounting bodies (0.9), plus 5.9 journals not included in the ABS (2008) listing. This latter category includes some (mainly lower quality) refereed journals together with professional magazines and newspapers.

${ }^{25}$ Unfortunately, we have no means of identifying any such chairs ex ante, so we have kept all observations in the analysis; the potential impact of this on the reported results is likely to be minimal.

${ }^{26}$ The information used included professorial title (if any), stated research interests, teaching specialisms, the nature (title and journal placement) of outputs and personal knowledge. While this necessarily involved a degree 
of subjectivity, a high level of consistency was achieved between the researchers: just 3 individuals were reclassified as a result of the different initial judgements.

${ }^{27}$ The 4 years is actually 3 years pre-promotion and 1 year post-promotion, on average, as described earlier for the 10 year data. Further, the analysis of internal/external promotions and gender in Table 3 was repeated on this 4 year data with identical conclusions (though obviously based on smaller numbers of outputs); i.e. there is no evidence of a difference between internal and external promotions or between pre-promotion outputs by males and females.

${ }^{28}$ There are 9 A\&F journals ranked as $4 *$ in ABS (2008) representing $7.2 \%$ of the 125 A\&F journals therein; 8 of the 9 are edited and published in the US with papers authored by US academics in the main. Overall in ABS (2008), $10 \%$ of the total of 1,025 journals are categorised as $4 *$. 


\section{REFERENCES}

AAA (2008). Accounting Faculty in U.S. Colleges and Universities: Status and Trends, 19932004. Sarasota, FL: American Accounting Association.

AACSB (2003). Report of the Doctoral Faculty Commission to AACSB International's Board of Directors. Tampa, FL: AACSB.

ABS (2008). The Association of Business Schools Academic Journal Quality Guide (Version 2). C. Harvey, H. Morris and A. Kelly (eds). London: The Association of Business Schools.

ABS (2009). The Association of Business Schools Academic Journal Quality Guide (Version 3). A. Kelly, H. Morris, M. Rowlinson and C. Harvey (eds). London: The Association of Business Schools.

ACCA (2007). [http://www.vnunet.com/accountancyage/news/2201659/acca-finds-lackgender; visited $27^{\text {th }}$ January 2009]

Baker, S., Choi, S.J. and Gulati, M. (2006). 'The rat race as an information-forcing device'. Indiana Law Journal, 81: 53-82.

Ballas, A. and Theoharakis, V. (2003). 'Exploring diversity in accounting through faculty journal perceptions'. Contemporary Accounting Research, 20(4): 619-644.

Beattie, V. and Davie, E. (2006). 'Theoretical studies of the historical development of the accounting discipline: A review and evidence'. Accounting, Business and Financial History, 16(1): 1-25.

Beattie, V. and Goodacre, A. (2004). 'Publishing patterns within the UK accounting and finance academic community'. British Accounting Review, 36(1): 7-44.

Beattie, V. and Goodacre, A. (2006). 'A new method for ranking academic journals in accounting and finance'. Accounting and Business Research, 36(2): 65-91.

Beattie, V.A. and Ryan, R.J. (1989). 'Performance indices and related measures of journal reputation in accounting'. British Accounting Review, 21(3): 267-278.

Beattie, V.A. and Ryan, R.J. (1991). 'The impact of non-serial publications on research in accounting and finance'. Abacus, 27(1): 32-49.

Borokhovich, K.A., Bricker, R.J., Brunarski, K.R. and Simkins, B.J. (1995). 'Finance research productivity and influence'. Journal of Finance, 50(5), 1691-1717.

Brinn, T., Jones, M.J. and Pendlebury, M. (1996). 'UK accountants' perceptions of research journal quality'. Accounting and Business Research, 26(3): 265-278.

Brinn, T., Jones, M.J. and Pendlebury, M. (2001). 'Why do UK accounting and finance academics not publish in top US journals?'. British Accounting Review, 33(2): 223232. 
British Accounting Review Research Register (various years), $1^{\text {st }}$ to thirteenth editions, Academic Press/Elsevier.

Brown, R., Jones, M. and Steele, A. (2007). 'Still flickering at the margins of existence? Publishing patterns and themes in accounting and finance research over the last two decades'. British Accounting Review, 39(2): 125-151.

Buckless, F., Ravenscroft, S. and Baldwin, A. (1998). 'Educational qualifications and gender: Accounting for women as adjuncts'. Advances in Public Interest Accounting, 9: 133156.

Carmona, S. (2006). 'Performance reviews, the impact of accounting research and the role of publication forms'. Advances in Accounting, 22: 241-267.

Chan, K.C., Fok, R.C.W. and Pan, M-S. (2000). 'Citation-based finance journal rankings: an update'. Financial Practice and Education, 10(1): 132-141.

Chow, C.W., Haddad, K., Singh, G. and Wu, A. (2008). 'A citation analysis of the top-ranked management and financial accounting journals'. International Journal of Managerial and Financial Accounting, 1(1): 29-44.

Christensen, A.L., Finger, C.A. and Latham, C.K. (2002). 'New accounting scholars' publications in accounting and non-accounting journals'. Issues in Accounting Education, 17(3): 233-251.

Churchman, D. (2002). 'Voices of the academy: academics' responses to the corporatizing of academia'. Critical Perspectives on Accounting, 13(5/6): 643-656.

Dwyer, P.D. (1994). 'Gender differences in the scholarly activities of accounting academics: an empirical investigation'. Issues in Accounting Education, 9(2): 231-246.

Ellison, G. (2002). 'Evolving standards for academic publishing: A $q-r$ theory'. Journal of Political Economy, 110(5): 947-93.

Faria, J.R. (2003). 'What type of economist are you: $r$-strategist or $K$-strategist?'. Journal of Economic Studies, 30(2): 144-154.

Fishe, R.P.H. (1998). 'What are the research standards for full professor of finance?'. Journal of Finance, 53(3): 1053-1079.

Fogarty, T.J. (2004). 'Sustained research productivity in accounting: a study of the senior cohort'. Global Perspectives on Accounting Education, 1: 31-58.

Gendron, Y. (2008). 'Constituting the academic performer: The spectre of superficiality and stagnation in academia'. European Accounting Review, 17(1): 97-127.

Glover, S.M., Prawitt, D.F. and Wood, D.A. (2006). 'Publication records of faculty promoted at the top 75 accounting research programs'. Issues in Accounting Education, 21(3): 195-218.

Gray, R., Guthrie, J. and Parker, L. (2002). 'Rites of passage and the self-immolation of academic accounting labour: an essay exploring exclusivity versus mutuality in accounting scholarship'. Accounting Forum, 26(1): 1-30. 
Harzing, A-W. (2008), Journal Quality List $\left[32^{\text {nd }}\right.$ edition: 26 September 2008, available at http://www.harzing.com]

Hermanson, D.R. (2008). 'What I have learned so far: Observations on managing an academic accounting career'. Issues in Accounting Education, 23(1): 53-66.

Higgs, D. (2003). Review of the Role and Effectiveness of Non-executive Directors. [http://www.berr.gov.uk/files/file23012.pdf, visited $27^{\text {th }}$ January 2009].

Higher Education Academy (2009). Reward and Recognition of Teaching in Higher Education. York: The Higher Education Academy.

Hopwood, A.G. (2008). 'Changing pressures on the research process: On trying to research in an age when curiosity is not enough'. European Accounting Review, 17(1): 87-96.

Humphrey, C., Moizer, P. and Owen, D. (1995). 'Questioning the value of the research selectivity process in British university accounting'. Accounting, Auditing \& Accountability Journal, 8(3): 141-164.

Jones, M.J. and Roberts, R. (2005). 'International publishing patterns: an investigation of leading UK and US accounting and finance journals', Journal of Business Finance \& Accounting, 32 (5\&6): 1107-1140.

Link, A.N., Swann, C.A. and Bozeman, B. (2008). 'A time allocation study of university faculty'. Economics of Education Review, 27(4): 363-374.

Lukka, K. and Kasanen, E. (1996). 'Is accounting a global or a local discipline? Evidence from major research journals'. Accounting, Organizations and Society, 21(7/8): 755773.

Mann, G. and Ormundson, J. (1991). Publication Productivity and Promotion of Accounting Faculty Women: A Comparative Study. Sarasota, FL: American Accounting Association.

Moizer, P. (2009). 'Publishing in accounting journals: a fair game?'. Accounting, Organizations and Society, 34(2): 285-304.

Neumann, R. and Guthrie, J. (2002). 'The corporatization of research in Australian higher education'. Critical Perspectives on Accounting, 13(5/6): 721-741.

Parker, J. (2008). 'Comparing research and teaching in university promotion criteria'. Higher Education Quarterly, 62(3): 237-251.

Parker, L.D. (2002). 'It's been a pleasure doing business with you: a strategic analysis and critique of university change management'. Critical Perspectives on Accounting, 13(5/6): 603-619.

Parker, L., Guthrie, J. and Gray, R. (1998). 'Accounting and management research: passwords from the gatekeepers'. Accounting, Auditing \& Accountability Journal, 11(4): 371402. 
Plumlee, R.D., Kachelmeier, S.J., Madeo, S.A., Pratt, J.H. and Krull, G. (2005). Report of the AAA/AAPLG Ad Hoc Committee to Assess the Supply and Demand for Accounting Ph.D's. Sarasota, FL: American Accounting Association. [Available at http://aaahq.org/about/reports/FINAL PhD Report.pdf]

Plumlee, R.D., Kachelmeier, S.J., Madeo, S.A., Pratt, J.H. and Krull, G. (2006). 'Assessing the shortage of accounting faculty'. Issues in Accounting Education, 21(2): 113-125.

Puxty, A.G., Sikka, P. and Willmott, H.C. (1994). 'Systems of surveillance and the silencing of UK academic accounting labour'. British Accounting Review, 26(2): 137-171.

RAE (2001). http://www.hero.ac.uk/rae/.

RAE (2008). http://www.rae.ac.uk/.

Raffournier, B. and Schatt, A. (2010). 'Is European research fairly reflected in academic journals? An investigation of possible non-mainstream and language barriers.' European Accounting Review, 19(1): 161-190.

Rama, D.V., Raghunandan, K., Logan, L.B. and Barkman, B.V. (1997). 'Gender differences in publications by promoted faculty'. Issues in Accounting Education, 12(2): 353365.

Read, W.J., Rama, D.V. and Raghunandan, K. (1998). 'Are publication requirements for accounting faculty promotions still increasing?'. Issues in Accounting Education, 13(2): 327-339.

REF (2009). Research Excellence Framework: Second consultation on the assessment and funding of research. Bristol: Higher Education Funding Council for England.

Reinstein, A. and Calderon, T.G. (2006). 'Examining accounting departments' rankings of the quality of accounting journals'. Critical Perspectives on Accounting, 17(4): 457-490.

Saravanamuthu, K. and Tinker, T. (2002). 'The university in the new corporate world'. Critical Perspectives on Accounting, 13(5/6): 545-554.

Schinski, M., Kugler, A. and Wick, W. (1998). 'Perceptions of the academic finance profession regarding publishing and the allocation of credit in coauthorship situations'. Financial Practice and Education, 8(1): 60-67.

Seggie, S.H. and Griffith, D.A. (2009). 'What does it take to get promoted in marketing academia? Understanding exceptional publication productivity in the leading marketing journals'. Journal of Marketing, 73(1): 122-132.

Sharman, A, (2008). 'New universities: Another year of the great divide'. The Independent on Sunday, Thursday, 24 April 2008. [accessed online at http://www.independent.co.uk/news/education/higher/new-universities-another-yearof-the-great-divide-814361.html on 24 January 2009]

Stewart, P. and Ornstein, M. (2009). 'Gender and promotion at Canadian universities'. Canadian Review of Sociology, 46(1): 59-85. 
Street, D.L. and Baril, C.P. (1994). 'Scholarly accomplishments in promotion and tenure decisions of accounting faculty'. Journal of Accounting Education, 12(2): 121-139.

Street, D.L., Baril, C.P. and Benke, R.L. (1993). 'Research, teaching and service in promotion and tenure decisions of accounting faculty'. Journal of Accounting Education, 11(1): 43-60.

Streuly, C.A. and Maranto, C.L. (1994). 'Accounting faculty research productivity and citations: are there gender differences?'. Issues in Accounting Education, 9(2): 247258.

Swanson, E.P. (2004). 'Publishing in the majors: A comparison of accounting, finance, management and marketing'. Contemporary Accounting Research, 21(1): 223-255.

Tinker, T. (2006). 'Politics of the academic workplace: Editorial report on a progressive journal assessment exercise'. Critical Perspectives on Accounting, 17(6): 703-716.

Trieschmann, J.S., Dennis, A.R., Northcraft, G.B. and Niemi, A.W. (2000). 'Serving multiple constituencies in business schools: M.B.A. program versus research performance'. Academy of Management Journal, 43(6): 1130-1141.

Tripathy, N. and Ganesh, G.K. (1996). 'Evaluation, promotion, and tenure of finance faculty: the evaluators' perspective'. Financial Practice and Education, 6(1): 46-53.

UCEA (2008). Recruitment and retention of staff in Higher Education 2008. London: Universities \& Colleges Employers Association.

Van Fleet, D.D., McWilliams, A. and Siegel, D.S. (2000). 'A theoretical and empirical analysis of journal rankings: the case of formal lists'. Journal of Management, 26(5): 839-861.

Wedlin, L. (2006). Ranking Business Schools: Forming Fields, Identities and Boundaries in International Management Education. Cheltenham: Edward Elgar.

Wedlin, L. (2007). 'The role of rankings in codifying a business school template: classifications, diffusion and mediated isomorphism in organizational fields'. European Management Review, 4(1): 24-39.

Willmott, H. (1995). 'Managing the academics: commodification and control in the development of university education in the UK'. Human Relations, 48(9): 993-1027.

Woodside, A.G. (2009). 'Journal and author impact metrics: an editorial'. Journal of Business Research, 62(1): 1-4.

Young, P. (2006). 'Out of balance: lecturers' perceptions of differential status and rewards in relation to teaching and research'. Teaching in Higher Education, 11(2): 191-202.

Zeff, S.A. (1996). 'A study of academic research journals in accounting'. Accounting Horizons, 10(3): 158-177. 


\section{Appendix 1: Explanation of promotion timing treatment}

Promotions to professor are obtained by comparing each individual's employment status between subsequent versions of the biennial British Accounting Review Research Register (BAR RR). A change (typically) from Senior Lecturer to Professor identifies a promotion. However, the date of promotion is not usually available, so the timing of promotion can only be identified as occurring within the two year period covered by the Register identifying a professor for the first time. On average, this means that promotions take place half-way through the two year period. We categorise all publications in this two year period as 'pre-promotion' which means that, on average, we include 1 year of post-promotion publications. Given the imprecision of the promotion date, this is almost unavoidable - indeed it is useful in that it implicitly allows for one year of 'forthcoming papers', on average, which would typically be taken into account in promotion decisions.

To clarify the methods applied:

a) promotion in a particular 'year' means identified in a particular register. For example, Xxxxxxx was first listed as a professor in the 1998 Register so is identified in the study as promoted in 1998. However, Xxxxxxx was actually promoted to professor in September 1997 (per the Register). In general, the precise date/year of promotion is unknown, but it is known that it occurs within a particular two-year period (as covered by the particular BAR RR).

On average this would mean that someone first listed as a professor in 1998 was promoted on 31 Dec 1996 (as the 1998 BAR RR deals with 1996 and 1997 publication outputs and other information such as role changes).

b) the ' 10 year' data analysis for an individual promoted in ' 1998 ' includes all publications in years 1988 through 1997; i.e. actually 10 years of outputs including 1 year beyond the reported promotion 'year', on average: 1 year of post-promotion outputs (1997) and 9 years pre-promotion (1988 through 1996).

c) the additional '4 year' analysis then includes 1994 through 1997, including 1 year of postpromotion outputs, on average (consistent with the logic above).

The diagram below illustrates the method and publications included as pre-promotion.

Timings for 1998 promotion 'year'

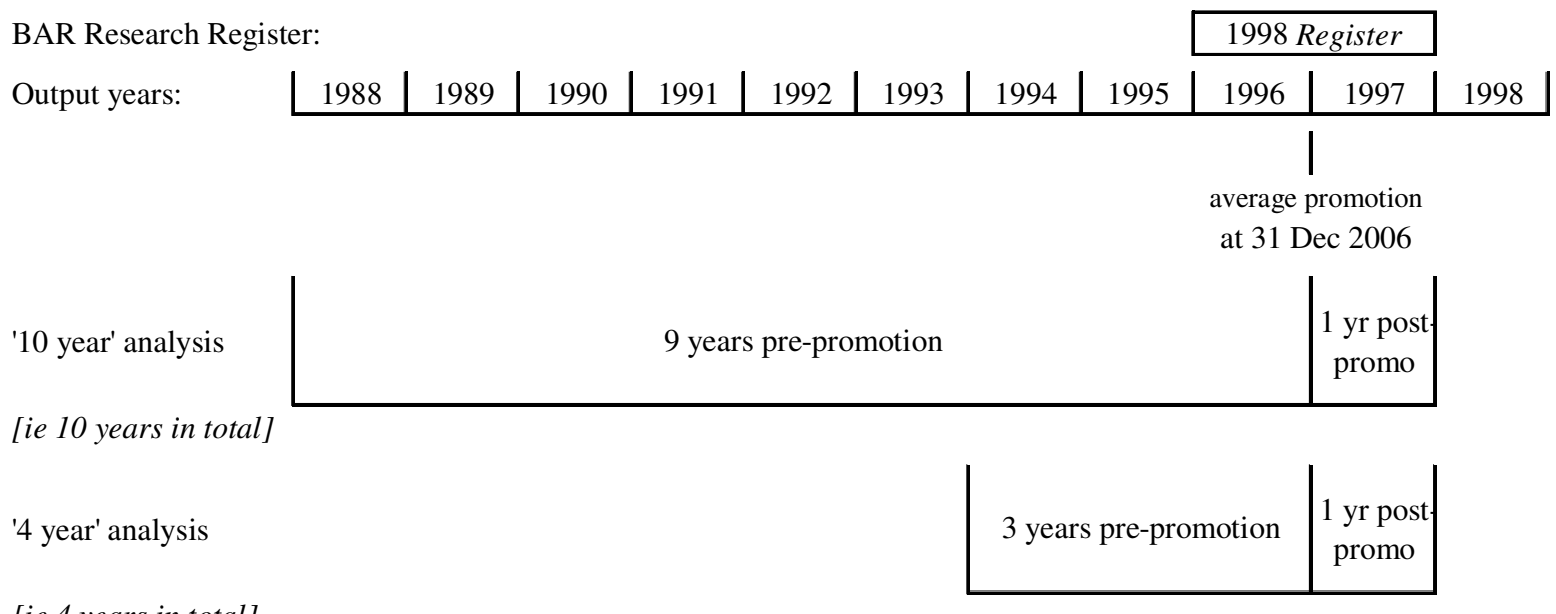

[ie 4 years in total] 
Appendix 2: Alphabetical list of promotion institutions represented in the data

\begin{tabular}{|c|c|c|}
\hline Institution (post-promo) & $\begin{array}{c}\text { Post- } \\
\text { 1992/Irish }\end{array}$ & No of promos \\
\hline Aberdeen University & & 2 \\
\hline Aberystwyth University & & 1 \\
\hline Aston University & & 3 \\
\hline Birmingham University & & 2 \\
\hline Bournemouth University & post-1992 & 1 \\
\hline Bradford University & & 1 \\
\hline Brighton University & post-1992 & 1 \\
\hline Bristol University & & 3 \\
\hline Buckingham University & post-1992 & 1 \\
\hline Cambridge University & & 1 \\
\hline Cardiff, University of Wales & & 6 \\
\hline Cass Business School [incl City Univ pre 04] & & 6 \\
\hline Central Lancashire University & post-1992 & 1 \\
\hline Dublin City University & Irish & 2 \\
\hline Dublin, University College & Irish & 1 \\
\hline Dundee University & & 4 \\
\hline Durham University Business School & & 2 \\
\hline East Anglia University & & 1 \\
\hline Edinburgh University & & 1 \\
\hline Essex University & & 6 \\
\hline Exeter University & & 1 \\
\hline Glamorgan University & post-1992 & 1 \\
\hline Glasgow Caledonian University & post-1992 & 3 \\
\hline Glasgow University & & 7 \\
\hline Heriot-Watt University & & 2 \\
\hline Hertfordshire University & post-1992 & 1 \\
\hline Huddersfield University & post-1992 & 2 \\
\hline Hull University & & 1 \\
\hline Keele University & & 1 \\
\hline Kingston University & post-1992 & 1 \\
\hline Lancaster University & & 3 \\
\hline Leeds Metropolitan University & post-1992 & 1 \\
\hline Leeds University & & 1 \\
\hline Liverpool University & & 1 \\
\hline London Business School & & 3 \\
\hline London Royal Holloway & & 1 \\
\hline London School of Economics & & 2 \\
\hline London, Imperial College & & 1 \\
\hline Loughborough University & & 2 \\
\hline Manchester Metropolitan & post-1992 & 1 \\
\hline Manchester University & & 7 \\
\hline Manchester, UMIST & & 2 \\
\hline Middlesex University & post-1992 & 1 \\
\hline Newcastle University & & 1 \\
\hline Northumbria at Newcastle & post-1992 & 1 \\
\hline Nottingham Trent University & post-1992 & 1 \\
\hline Nottingham University & & 5 \\
\hline Open University & & 1 \\
\hline Oxford Brookes University & post-1992 & 1 \\
\hline Paisley University & post-1992 & 1 \\
\hline Plymouth University & post-1992 & 1 \\
\hline Portsmouth University & post-1992 & 1 \\
\hline Queen's University & & 2 \\
\hline Robert Gordon University & post-1992 & 1 \\
\hline Sheffield Hallam University & post-1992 & 2 \\
\hline Sheffield University & & 6 \\
\hline South Bank University & post-1992 & 1 \\
\hline Southampton University & & 2 \\
\hline Stirling University & & 7 \\
\hline Strathclyde University & & 5 \\
\hline Ulster University & post-1992 & 3 \\
\hline Warwick University & & 2 \\
\hline West of England University Bristol & post-1992 & 4 \\
\hline Total number of promotions & & 140 \\
\hline
\end{tabular}

\begin{tabular}{|l|c|c|c|}
\hline & $\begin{array}{c}\text { Post- } \\
\mathbf{1 9 9 2 / I r i s h}\end{array}$ & Pre-1992 & Overall \\
\hline Total number of Institutions in sample & $\mathbf{2 5}$ & $\mathbf{3 9}$ & $\mathbf{6 4}$ \\
\hline Total number in 2008 BAR RR & 56 & 53 & 109 \\
\hline$\%$ of 2008 BAR RR & $45 \%$ & $74 \%$ & $59 \%$ \\
\hline
\end{tabular}


Table 1: Cross-tabulations of sample characteristics of promotions to professor 19922007

Panel A

Pre-1992

Post-1992

Total

\begin{tabular}{|c|c|c|c|c|c|c|c|c|c|}
\hline $1992-3$ & 1994-5 & 1996-7 & 1998-9 & $2000-1$ & $2002-3$ & 2004-5 & 2006-7 & Total & $\%$ \\
\hline 8 & 14 & 8 & 13 & 14 & 14 & 18 & 16 & 105 & $75 \%$ \\
\hline 4 & 4 & 2 & 9 & 4 & 7 & 3 & 2 & 35 & $25 \%$ \\
\hline 12 & 18 & 10 & 22 & 18 & 21 & 21 & 18 & 140 & $100 \%$ \\
\hline
\end{tabular}

Fisher's Exact Test $=7.36(\mathrm{p}=0.388)$

Panel B

Internal

External

Internal \%

\begin{tabular}{|c|c|c|c|c|c|c|c|c|c|}
\hline $1992-3$ & 1994-5 & 1996-7 & 1998-9 & $2000-1$ & $2002-3$ & 2004-5 & 2006-7 & Total & $\%$ \\
\hline 7 & 10 & 8 & 14 & 14 & 15 & 10 & 12 & 90 & $64 \%$ \\
\hline 5 & 8 & 2 & 8 & 4 & 6 & 11 & 6 & 50 & $36 \%$ \\
\hline 12 & 18 & 10 & 22 & 18 & 21 & 21 & 18 & 140 & $100 \%$ \\
\hline
\end{tabular}

Fisher's Exact Test $=6.17(\mathrm{p}=0.528)$

Panel C

Male

Female

\begin{tabular}{cccccccccc}
$\mathbf{1 9 9 2 - 3}$ & $\mathbf{1 9 9 4 - 5}$ & $\mathbf{1 9 9 6 - 7}$ & $\mathbf{1 9 9 8 - 9}$ & $\mathbf{2 0 0 0 - 1}$ & $\mathbf{2 0 0 2 - 3}$ & $\mathbf{2 0 0 4 - 5}$ & $\mathbf{2 0 0 6 - 7}$ & Total & \% \\
12 & 17 & 8 & 19 & 16 & 14 & 14 & 13 & 113 & $81 \%$ \\
0 & 1 & 2 & 3 & 2 & 7 & 7 & 5 & 27 & \\
\hline 12 & 18 & 10 & 22 & 18 & 21 & 21 & 18 & 140 & \\
\hline \hline
\end{tabular}

Fisher's Exact Test $=11.93(\mathrm{p}=0.081)$

Panel D

Accounting

Finance/Acc\&Fin

\begin{tabular}{|c|c|c|c|c|c|c|c|c|c|}
\hline 1992-3 & 1994-5 & 1996-7 & 1998-9 & 2000-1 & 2002-3 & 2004-5 & 2006-7 & Total & $\%$ \\
\hline 10 & 14 & 6 & 20 & 14 & 14 & 15 & 8 & 101 & $72 \%$ \\
\hline 2 & 4 & 4 & 2 & 4 & 7 & 6 & 10 & 39 & $28 \%$ \\
\hline 12 & 18 & 10 & 22 & 18 & 21 & 21 & 18 & 140 & $100 \%$ \\
\hline
\end{tabular}

Fisher's Exact Test $=12.57(\mathrm{p}=0.074)$

Panel E

$$
\text { Pre-1992 Post-1992 Total }
$$

Male

Female

\begin{tabular}{ccc}
85 & 28 & 113 \\
20 & 7 & 27 \\
\hline 105 & 35 & 140 \\
\hline \hline
\end{tabular}

\begin{tabular}{lccc} 
Panel F & & & \\
& Int & Ext & Total \\
Male & 71 & 42 & 113 \\
Female & 19 & 8 & 27 \\
\cline { 2 - 4 } & 90 & 50 & 140 \\
\cline { 2 - 4 } &
\end{tabular}

Chi-sq $=0.00(\mathrm{p}=1.000)$

Chi-sq $=0.26(p=0.609)$

Panel G

Accounting

Finance/Acc\&Fin

$$
\text { Pre-1992 Post-1992 Total }
$$

\begin{tabular}{ccc}
69 & 32 & 101 \\
36 & 3 & 39 \\
\hline 105 & 35 & 140 \\
\hline \hline
\end{tabular}

Chi-sq $=7.41(p=0.007)$ 
Table 2: Summary of outputs in 10 years prior to promotion to professor - full sample and partitioned by institution type

\begin{tabular}{|c|c|c|c|c|c|c|c|c|c|c|}
\hline & \multicolumn{4}{|c|}{ ABS- listed journals } & \multirow{2}{*}{$\begin{array}{l}\text { Total } \\
\text { ABS }\end{array}$} & \multirow{2}{*}{$\begin{array}{c}\text { Total } \\
\text { non-ABS }\end{array}$} & \multirow{2}{*}{$\begin{array}{c}\text { Total } \\
\text { Outputs }\end{array}$} & \multirow{2}{*}{$\begin{array}{l}\text { Weighted } \\
\text { ABS Score }\end{array}$} & \multirow{2}{*}{$\begin{array}{c}\text { Total } \\
3 *+4^{*}\end{array}$} & \multirow{2}{*}{$\begin{array}{c}3^{*}+4^{*} \\
\text { of total A }\end{array}$} \\
\hline & $4 *$ & $3 *$ & $2 *$ & $\mathbf{1}^{*}$ & & & & & & \\
\hline \multicolumn{11}{|c|}{ Panel A: Overall results $(n=140)$} \\
\hline Mean & 0.7 & 4.6 & 2.3 & 1.0 & 8.6 & 11.8 & 20.4 & 2.49 & 5.2 & $59 \%$ \\
\hline Minimum & 0.0 & 0.0 & 0.0 & 0.0 & 0.0 & 0.0 & 3.0 & 0.00 & 0.0 & $0 \%$ \\
\hline 16.5th percentile & 0.0 & 1.0 & 0.0 & 0.0 & 4.0 & 3.0 & 10.0 & 2.08 & 1.9 & $26 \%$ \\
\hline Q1 & 0.0 & 2.0 & 0.0 & 0.0 & 5.0 & 4.0 & 12.0 & 2.25 & 2.0 & $38 \%$ \\
\hline Median & 0.0 & 4.0 & 2.0 & 0.0 & 8.0 & 10.0 & 17.5 & 2.57 & 5.0 & $63 \%$ \\
\hline Q3 & 1.0 & 7.0 & 3.0 & 1.0 & 12.0 & 16.0 & 25.3 & 2.92 & 7.0 & $85 \%$ \\
\hline 83.5th percentile & 1.0 & 8.0 & 4.1 & 2.0 & 13.0 & 18.0 & 30.0 & 3.00 & 9.0 & $92 \%$ \\
\hline Maximum & 9.0 & 15.0 & 10.0 & 7.0 & 21.0 & 55.0 & 73.0 & 4.00 & 17.0 & $100 \%$ \\
\hline
\end{tabular}

Panel B: Pre-1992 vs post-1992 institutions

Promotion to pre-1992 institution $(n=105)$

$\begin{array}{lcccccccccc}\text { Mean } & \mathbf{0 . 8} & \mathbf{5 . 3} & \mathbf{2 . 5} & \mathbf{0 . 8} & \mathbf{9 . 4} & \mathbf{1 1 . 4} & \mathbf{2 0 . 8} & \mathbf{2 . 6 2} & \mathbf{6 . 2} & \mathbf{6 5 \%} \\ \text { Minimum } & 0.0 & 0.0 & 0.0 & 0.0 & 0.0 & 0.0 & 4.0 & 0.00 & 0.0 & 0 \% \\ \text { 16.5th percentile } & 0.0 & 1.2 & 0.0 & 0.0 & 4.0 & 3.0 & 10.2 & 2.29 & 2.0 & 38 \% \\ \text { Q1 } & 0.0 & 2.0 & 0.0 & 0.0 & 6.0 & 4.0 & 12.0 & 2.36 & 4.0 & 50 \% \\ \text { Median } & \mathbf{0 . 0} & \mathbf{5 . 0} & \mathbf{2 . 0} & \mathbf{0 . 0} & \mathbf{9 . 0} & \mathbf{9 . 0} & \mathbf{1 7 . 0} & \mathbf{2 . 6 7} & \mathbf{5 . 0} & \mathbf{6 7 \%} \\ \text { Q3 } & 1.0 & 8.0 & 4.0 & 1.0 & 13.0 & 16.0 & 27.0 & 3.00 & 9.0 & 88 \% \\ \text { 83.5th percentile } & 1.0 & 9.0 & 5.0 & 1.8 & 14.0 & 18.0 & 30.8 & 3.00 & 10.0 & 100 \% \\ \text { Maximum } & 9.0 & 15.0 & 10.0 & 7.0 & 21.0 & 55.0 & 73.0 & 4.00 & 17.0 & 100 \% \\ & & & & & & & & & & \\ \text { Promotion to post-1992 institution } & \mathbf{n}=\mathbf{3 5}) & \mathbf{1} & & & & & & & \\ \text { Mean } & \mathbf{0 . 1} & \mathbf{2 . 3} & \mathbf{1 . 9} & \mathbf{1 . 5} & \mathbf{5 . 9} & \mathbf{1 3 . 1} & \mathbf{1 9 . 0} & \mathbf{2 . 1 1} & \mathbf{2 . 5} & \mathbf{4 2 \%} \\ & & & & & & & & & & \\ \text { Minimum } & 0.0 & 0.0 & 0.0 & 0.0 & 0.0 & 1.0 & 3.0 & 0.00 & 0.0 & 0 \% \\ \text { 16.5th percentile } & 0.0 & 0.0 & 0.0 & 0.0 & 2.0 & 4.0 & 9.2 & 1.60 & 0.0 & 0 \% \\ \text { Q1 } & 0.0 & 1.0 & 0.0 & 0.0 & 3.0 & 5.0 & 11.0 & 1.73 & 1.0 & 14 \% \\ \text { Median } & \mathbf{0 . 0} & \mathbf{2 . 0} & \mathbf{1 . 0} & \mathbf{1 . 0} & \mathbf{6 . 0} & \mathbf{1 1 . 0} & \mathbf{1 8 . 0} & \mathbf{2 . 2 2} & \mathbf{2 . 0} & \mathbf{4 0 \%} \\ \text { Q3 } & 0.0 & 3.0 & 3.0 & 2.5 & 8.5 & 17.0 & 24.5 & 2.52 & 3.0 & 62 \% \\ \text { 83.5th percentile } & 0.0 & 4.8 & 3.0 & 3.0 & 9.0 & 18.8 & 26.6 & 2.86 & 5.4 & 79 \% \\ \text { Maximum } & 2.0 & 7.0 & 9.0 & 6.0 & 14.0 & 45.0 & 58.0 & 3.40 & 7.0 & 100 \% \\ & & & & & & & & & & \end{array}$

Significance of tests for difference between pre-1992 and post-1992 promotion mean outputs ${ }^{2}$

$* * *$

$* * *$

$* * * \quad * * * * *$

Notes

1. The 3 promotions to Irish universities are included within post-1992 institutions

2. Differences between means for pre-1992 and post-1992 institutions significant at $1 \%(* * *)$ and $5 \%(* *)$, respectively (2-tail t-test) 
Table 3: Association between pre-promotion publication portfolio and various characteristics

\begin{tabular}{|c|c|c|c|c|c|c|c|c|c|c|}
\hline & \multicolumn{4}{|c|}{ ABS- listed journals } & \multirow{2}{*}{$\begin{array}{l}\text { Total } \\
\text { ABS }\end{array}$} & \multirow{2}{*}{$\begin{array}{c}\text { Total } \\
\text { non-ABS }\end{array}$} & \multirow{2}{*}{$\begin{array}{c}\text { Total } \\
\text { Outputs }\end{array}$} & \multirow{2}{*}{$\begin{array}{c}\text { Weighted } \\
\text { ABS Score }\end{array}$} & \multirow{2}{*}{$\begin{array}{c}\text { Total } \\
3^{*}+4^{*}\end{array}$} & \multirow{2}{*}{$\begin{array}{c}3^{*}+4^{*} \% \\
\text { of total ABS }\end{array}$} \\
\hline & $4^{*}$ & $3 *$ & $2 *$ & $1^{*}$ & & & & & & \\
\hline \multicolumn{11}{|c|}{ Panel A: Internal vs external promotion ${ }^{1}$} \\
\hline \multicolumn{11}{|c|}{ Internal promotion $(\mathrm{n}=90)$} \\
\hline Mean & 0.7 & 4.9 & 2.5 & 1.0 & 9.1 & 12.2 & 21.3 & 2.47 & 5.6 & $\mathbf{5 8 \%}$ \\
\hline Median & 0.0 & 5.0 & 2.0 & 0.0 & 8.0 & 11.0 & 18.5 & 2.60 & 5.0 & $60 \%$ \\
\hline \multicolumn{11}{|c|}{ External promotion $(n=50)$} \\
\hline Mean & 0.5 & 4.0 & 2.1 & 1.0 & 7.6 & 11.2 & 18.8 & 2.54 & 4.5 & $61 \%$ \\
\hline Median & 0.0 & 3.5 & 2.0 & 0.0 & 7.0 & 10.0 & 15.0 & 2.52 & 4.0 & $67 \%$ \\
\hline \multicolumn{11}{|c|}{ Panel B: Male vs female promotions ${ }^{2}$} \\
\hline \multicolumn{11}{|c|}{ Male $(n=113)$} \\
\hline Mean & 0.7 & 4.7 & 2.1 & 1.0 & 8.5 & 12.0 & 20.5 & 2.55 & 5.4 & $62 \%$ \\
\hline Median & 0.0 & 4.0 & 2.0 & 0.0 & 8.0 & 11.0 & 18.0 & 2.63 & 5.0 & $67 \%$ \\
\hline \multicolumn{11}{|c|}{ Female $(n=27)$} \\
\hline Mean & 0.5 & 4.1 & 3.1 & 0.9 & 8.6 & 11.2 & 19.8 & 2.29 & 4.6 & $\mathbf{5 0 \%}$ \\
\hline Median & 0.0 & 5.0 & 2.0 & 0.0 & 9.0 & 8.0 & 17.0 & 2.40 & 5.0 & $50 \%$ \\
\hline \multicolumn{11}{|c|}{ Panel C: Accounting vs finance professors } \\
\hline \multicolumn{11}{|c|}{ C(i) Accounting professors $(n=101)$} \\
\hline Mean & 0.6 & 4.3 & 2.4 & 0.9 & 8.2 & 14.0 & 22.2 & 2.45 & 4.9 & $\mathbf{5 7 \%}$ \\
\hline Median & 0.0 & 4.0 & 2.0 & 0.0 & 8.0 & 12.0 & 20.0 & 2.50 & 5.0 & $59 \%$ \\
\hline \multicolumn{11}{|c|}{ C(ii) Finance professors $(n=33)^{3,4}$} \\
\hline Mean & 0.8 & 5.2 & 2.2 & 1.1 & 9.3 & 5.1 & 14.4 & 2.61 & 6.0 & $66 \%$ \\
\hline Median & 0.0 & 4.0 & 1.0 & 1.0 & 8.0 & 4.0 & 13.0 & 2.69 & 5.0 & $72 \%$ \\
\hline \multicolumn{11}{|c|}{ C(iii) Finance and accounting/finance professors $(n=39)^{3,4}$} \\
\hline Mean & 0.8 & 5.4 & 2.2 & 1.1 & 9.5 & 6.3 & 15.8 & 2.61 & 6.1 & $66 \%$ \\
\hline Median & 0.0 & 5.0 & 1.0 & 1.0 & 8.0 & 4.0 & 13.0 & 2.69 & 5.0 & $67 \%$ \\
\hline \multicolumn{11}{|c|}{ Significance of tests for difference between accounting and finance discipline professor mean outputs ${ }^{4}$} \\
\hline C(i) vs C(ii) & & & & & & $* * *$ & $* * *$ & & & \\
\hline C(i) vs C(iii) & & & & & & $* * *$ & $* * *$ & & & \\
\hline
\end{tabular}

Panel D: Time series analysis of mean pre-promotion outputs

\begin{tabular}{|c|c|c|c|c|c|c|c|c|c|c|c|}
\hline 'Year' of promotion ${ }^{5}$ & No of promos & & & & & & & & & & \\
\hline $1992-3$ & 12 & 0.4 & 2.6 & 0.9 & 0.2 & 4.1 & 16.3 & 20.3 & 2.48 & 3.0 & $66 \%$ \\
\hline $1994-5$ & 18 & 0.7 & 4.6 & 1.4 & 0.6 & 7.3 & 14.6 & 21.9 & 2.48 & 5.2 & $65 \%$ \\
\hline 1996-7 & 10 & 0.5 & 6.1 & 3.3 & 1.2 & 11.1 & 19.6 & 30.7 & 2.36 & 6.6 & $52 \%$ \\
\hline 1998-9 & 22 & 0.5 & 4.5 & 1.4 & 0.7 & 7.0 & 11.6 & 18.7 & 2.52 & 5.0 & $64 \%$ \\
\hline $2000-1$ & 18 & 0.8 & 4.8 & 3.4 & 1.2 & 10.2 & 11.2 & 21.4 & 2.63 & 5.6 & $58 \%$ \\
\hline $2002-3$ & 21 & 0.2 & 4.8 & 2.3 & 1.2 & 8.5 & 11.4 & 19.9 & 2.36 & 5.0 & $54 \%$ \\
\hline $2004-5$ & 21 & 0.6 & 4.6 & 3.4 & 0.9 & 9.5 & 9.6 & 19.0 & 2.49 & 5.2 & $53 \%$ \\
\hline $2006-7$ & 18 & 1.4 & 4.9 & 2.4 & 1.8 & 10.7 & 5.7 & 16.4 & 2.59 & 6.4 & $62 \%$ \\
\hline Significant mean diffe & & & & $* * *$ & & $* * *$ & $* *$ & & & & \\
\hline
\end{tabular}

Notes

1. None of the differences between means for internal and external promotions were significant at the $1 \%$ or $5 \%$ levels (2-tail t-test)

2. None of the differences between means for male and female promotions were significant at the $1 \%$ or $5 \%$ levels (2-tail t-test)

3. Five professors in the sample act at the interface between accounting and finance;

these five are excluded from C(ii) and included within C(iii), respectively

4. Differences between means for accounting and finance professors significant at $1 \%(* * *)$ and $5 \%(* *)$, respectively $(2$-tail t-test)

5. The 'year' of promotion identifies the two-year period during which the promotion occurred

6. ANOVA test; Tukey HSD post-hoc tests show:ABS $2 *$ has significantly lower means in 1992-3, 1998-9 than the highs in 2000-1, 2004-5

Total ABS has significantly lower means in 1992-3 than the highs in 1996-7, 2000-1, 2004-5 and 2006-7

Total non-ABS has significantly lower means in 2006-7 than the highs in 1992-3 and 1996-78 
Table 4: Summary of outputs in 4 years prior to promotion to professor

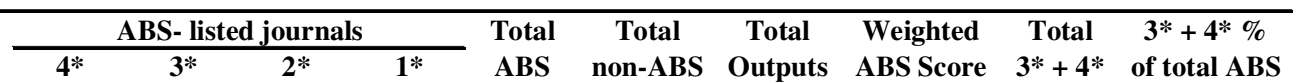

Overall results $(n=140)$

\begin{tabular}{|c|c|c|c|c|c|c|c|c|c|}
\hline Mean & 0.3 & 2.5 & 1.3 & 0.6 & 4.8 & 5.4 & 10.1 & 2.33 & 2.9 \\
\hline Minimum & 0.0 & 0.0 & 0.0 & 0.0 & 0.0 & 0.0 & 0.0 & 0.00 & 0.0 \\
\hline Median & 0.0 & 2.0 & 1.0 & 0.0 & 5.0 & 4.0 & 9.0 & 2.50 & 3.0 \\
\hline Maximum & 5.0 & 12.0 & 8.0 & 4.0 & 16.0 & 37.0 & 53.0 & 4.00 & 13.0 \\
\hline
\end{tabular}

Significance of tests for difference between 4 year and 10 year rates of output ${ }^{1}$

$\begin{array}{llllllrrrrr}\text { Mean } 10 \text { year [Table 2] } & 0.7 & 4.6 & 2.3 & 1.0 & 8.6 & 11.8 & 20.4 & 2.49 & 5.2 & 59 \% \\ \mathbf{4 / 1 0} \text { * Mean (10 year) } & \mathbf{0 . 3} & \mathbf{1 . 8} & \mathbf{0 . 9} & \mathbf{0 . 4} & \mathbf{3 . 4} & \mathbf{4 . 7} & \mathbf{8 . 2} & \mathbf{2 . 4 9} & \mathbf{2 . 1} & \mathbf{5 9 \%} \\ & & * * * & * * * & * * * & * * * & & * * * & \text { Note 2 } & * * * & \text { Note } 2\end{array}$

Notes

1. Test of whether mean of '4 year' $>4 / 10$ ths of mean '10 year' (1 tail t-test)

2. 4 year means for Weighted ABS Score and $3 *+4 * \%$ of total ABS are actually significantly less than $4 / 10$ ths of mean '10 year' at the $5 \%$ level ( 1 tail t-test)

3. $* * *(* *)$ represent significance at the $1 \%$ and $5 \%$ levels, respectively 
Table 5: OLS multivariate regressions of factors affecting pre-promotion portfolios for promotions to professor 1992-2007

\begin{tabular}{|c|c|c|c|c|c|c|c|c|c|c|}
\hline & & MODEL 1 & & & MODEL 2 & & & MODEL 3 & & \\
\hline & & \multicolumn{2}{|c|}{ all promotions } & & \multicolumn{2}{|c|}{ pre-1992 promotions } & & \multicolumn{2}{|c|}{ all promotions } & \\
\hline \multirow[t]{2}{*}{ Dependent variable: } & & \multicolumn{3}{|c|}{ No of ABS Journal papers } & \multicolumn{3}{|c|}{ No of ABS Journal papers } & \multicolumn{2}{|c|}{ Total no of outputs } & \\
\hline & $\operatorname{Exp}$ & & & & & & & & & \\
\hline Independent variables & sign & coeff & t-stat & & coeff & t-stat & & coeff & t-stat & \\
\hline post-1992 & - & -0.065 & -0.08 & & & & & 1.078 & 0.54 & \\
\hline internal & + & 0.324 & 0.65 & & 1.100 & 1.73 & * & 2.854 & 2.35 & ** \\
\hline female & $?$ & -0.563 & -0.94 & & -0.675 & -0.95 & & -0.907 & -0.61 & \\
\hline finance & $?$ & -0.287 & -0.46 & & -0.571 & -0.78 & & -4.496 & -3.15 & $* * *$ \\
\hline acc/fin & $?$ & 0.464 & 0.40 & & 0.445 & 0.37 & & -1.760 & -0.62 & \\
\hline $1992-3$ & $?$ & -3.599 & -3.34 & $* * *$ & -3.617 & -2.82 & *** & 2.784 & 1.10 & \\
\hline $1994-5$ & $?$ & -3.764 & -4.06 & *** & -3.572 & -3.36 & **** & -6.422 & -2.77 & $* * *$ \\
\hline 1996-7 & $?$ & -2.970 & -2.73 & $* * *$ & -2.098 & -1.67 & $*$ & 0.268 & 0.10 & \\
\hline $1998-9$ & $?$ & -2.982 & -3.25 & $* * *$ & -2.457 & -2.26 & *** & -4.941 & -2.18 & $* *$ \\
\hline $2000-1$ & $?$ & -1.460 & -1.57 & & -1.928 & -1.84 & $*$ & -1.828 & -0.80 & \\
\hline $2002-3$ & $?$ & -1.452 & -1.67 & * & -1.474 & -1.48 & & 0.221 & 0.10 & \\
\hline $2004-5$ & $?$ & -1.014 & -1.21 & & -0.729 & -0.79 & & -0.278 & -0.13 & \\
\hline total no of ABS papers (4yr) & - & 0.978 & 11.93 & $* * *$ & 0.979 & 10.55 & *** & & & \\
\hline total outputs (4yr) & - & & & & & & & 1.402 & 16.97 & $* * *$ \\
\hline Russell Group & + & -0.226 & -0.37 & & -0.035 & -0.05 & & 1.814 & 1.20 & \\
\hline 1994 Group & + & -0.429 & -0.52 & & -0.350 & -0.41 & & 4.096 & 2.06 & ** \\
\hline RAE 2008 score & + & 1.635 & 1.60 & & 1.618 & 1.35 & & 1.187 & 0.48 & \\
\hline non-ABS outputs (excl reports) & - & 0.055 & 1.91 & * & 0.058 & 1.59 & & & & \\
\hline sole-authored ABS papers & - & 0.342 & 3.83 & $* * *$ & 0.312 & 3.04 & **** & 0.446 & 2.10 & ** \\
\hline total no of research reports & - & 0.223 & 1.41 & & 0.081 & 0.41 & & & & \\
\hline Constant & & 0.247 & 0.09 & & -0.135 & -0.04 & & 1.722 & 0.25 & \\
\hline $\mathbf{n}$ & & & 137 & & & 105 & & & 137 & \\
\hline Adj Rsq & & & 0.73 & & & 0.72 & & & 0.75 & \\
\hline $\mathbf{F}$ & & & 20.58 & **** & & 16.06 & *** & & 24.53 & **** \\
\hline
\end{tabular}

\section{Notes}

$* * *, * *$ and $*$ represent significance at the $1 \%, 5 \%$ and $10 \%$ levels respectively (2-tail)

\section{Dependent variables}

No of ABS Journal papers: total number of papers published in journals listed in ABS (2008) over the 10 year period 'prior to' promotion; Total no of outputs: total number of outputs of any type over the 10 year period 'prior to' promotion.

\section{Independent variables}

post-1992: promotion to, or at, a post-1992 institution (D); internal: internal promotion (D); female: female (D); finance: academic working within the finance sub-discipline (D); acc/fin: academic working at the interface between accounting and finance sub-disciplines (D); time dummies: 1992-3, 1994-5, 1996-7, 1998-9, 2000-1, 2002-3, 2004-5 represent promotion within the named two year period (D); promotion in 2006-7 is the base period (with no dummy); total no of ABS papers (4yr): total number of papers published in journals listed in ABS (2008) over the 4 year period 'prior to' promotion; total outputs $(4 y r)$ : total number of outputs of any type over the 4 year period 'prior to' promotion; Russell Group: promotion to, or at, one of the 20 universities in the Russell Group (D); 1994 Group: promotion to, or at, one of the 18 universities in the 1994 Group (D); RAE 2008 score: GPA of the promoting institution's submission to the UK Research Assessment Exercise 2008, measured as the average of the GPA scores received for the submissions to the "Business and Management" and "Accounting and Finance" Panels, weighted by the number of staff submitted to each panel; non-ABS outputs (excl reports): total number of outputs excluding ABS journal papers and research reports (professional and other) over the 10 year period 'prior to' promotion; sole-authored ABS papers: number of sole-authored ABS-listed journal papers over the 10 year period 'prior to' promotion; total no of research reports: total number of research reports (professional and other) over the 10 year period 'prior to' promotion. 
Table 6: Journals included in professor promotion portfolios

\begin{tabular}{|c|c|c|c|c|c|c|}
\hline Journal & ISSN & Subj group & ABS Grade & $\begin{array}{c}\begin{array}{c}\text { no of } \\
\text { papers }\end{array} \\
\end{array}$ & $\begin{array}{c}\begin{array}{c}\% \text { of } \\
\text { totABS }\end{array} \\
\end{array}$ & Cum\% \\
\hline Journal of Business Finance \& Accounting & 0306-686X & $\mathrm{A} \& \mathrm{~F}$ & 3 & 81 & $6.8 \%$ & $6.8 \%$ \\
\hline Accounting and Business Research & $0001-4788$ & $\mathrm{~A} \& \mathrm{~F}$ & 3 & 78 & $6.5 \%$ & $13.3 \%$ \\
\hline British Accounting Review & 0890-8389 & $\mathrm{A} \& \mathrm{~F}$ & 3 & 66 & $5.5 \%$ & $18.8 \%$ \\
\hline Critical Perspectives on Accounting & $1045-2354$ & $\mathrm{~A} \& \mathrm{~F}$ & 3 & 60 & $5.0 \%$ & $23.8 \%$ \\
\hline Accounting, Auditing \& Accountability Journal & 0951-3574 & $\mathrm{A} \& \mathrm{~F}$ & 3 & 52 & $4.3 \%$ & $28.1 \%$ \\
\hline Accounting Education: An International Journal & $0963-9284$ & MAN DEV \& EDU & 2 & 52 & $4.3 \%$ & $32.4 \%$ \\
\hline Accounting, Organizations and Society & $0361-3682$ & $\mathrm{~A} \& \mathrm{~F}$ & 4 & 42 & $3.5 \%$ & $35.9 \%$ \\
\hline European Accounting Review & 0963-8180 & $\mathrm{A} \& \mathrm{~F}$ & 3 & 35 & $2.9 \%$ & $38.9 \%$ \\
\hline Financial Accountability and Management & $0267-4424$ & $\mathrm{~A} \& \mathrm{~F}$ & 3 & 32 & $2.7 \%$ & $41.5 \%$ \\
\hline Management Accounting Research & $1044-5005$ & $\mathrm{~A} \& \mathrm{~F}$ & 3 & 29 & $2.4 \%$ & $44.0 \%$ \\
\hline Applied Financial Economics & 0960-3107 & $\mathrm{A} \& \mathrm{~F}$ & 2 & 25 & $2.1 \%$ & $46.0 \%$ \\
\hline Public Money \& Management & $0954-0962$ & PUB SEC & 2 & 24 & $2.0 \%$ & $48.0 \%$ \\
\hline Accounting Forum & $0155-9982$ & $\mathrm{~A} \& \mathrm{~F}$ & 2 & 22 & $1.8 \%$ & $49.9 \%$ \\
\hline Journal of Banking \& Finance & $0378-4266$ & $\mathrm{~A} \& \mathrm{~F}$ & 3 & 17 & $1.4 \%$ & $51.3 \%$ \\
\hline Corporate Governance: An International Review & $0964-8410$ & ETH-GOV & 3 & 16 & $1.3 \%$ & $52.6 \%$ \\
\hline Journal of Applied Accounting Research & $0967-5426$ & $\mathrm{~A} \& \mathrm{~F}$ & 2 & 16 & $1.3 \%$ & $54.0 \%$ \\
\hline European Financial Management & $1354-7798$ & $\mathrm{~A} \& \mathrm{~F}$ & 3 & 15 & $1.3 \%$ & $55.2 \%$ \\
\hline European Journal of Finance & $1351-847 \mathrm{X}$ & $\mathrm{A} \& \mathrm{~F}$ & 3 & 15 & $1.3 \%$ & $56.5 \%$ \\
\hline Irish Accounting Review & $0791-9638$ & $\mathrm{~A} \& \mathrm{~F}$ & 1 & 15 & $1.3 \%$ & $57.7 \%$ \\
\hline Accounting, Business and Financial History & $0958-5206$ & BUS HIST & 2 & 13 & $1.1 \%$ & $58.8 \%$ \\
\hline Managerial Auditing Journal & $0268-6902$ & $\mathrm{~A} \& \mathrm{~F}$ & 1 & 13 & $1.1 \%$ & $59.9 \%$ \\
\hline Journal of International Accounting, Auditing, \& Taxation & $1061-9518$ & $\mathrm{~A} \& \mathrm{~F}$ & 2 & 12 & $1.0 \%$ & $60.9 \%$ \\
\hline Managerial Finance & $0307-4358$ & $\mathrm{~A} \& \mathrm{~F}$ & 1 & 12 & $1.0 \%$ & $61.9 \%$ \\
\hline Applied Economics Letters & $1350-4851$ & ECON & 2 & 11 & $0.9 \%$ & $62.8 \%$ \\
\hline International Journal of Accounting & $0020-7063$ & $\mathrm{~A} \& \mathrm{~F}$ & 3 & 11 & $0.9 \%$ & $63.7 \%$ \\
\hline British Journal of Management & $1045-3172$ & GEN MAN & 3 & 10 & $0.8 \%$ & $64.6 \%$ \\
\hline International Journal of Auditing & $1090-6738$ & $A \& F$ & 2 & 10 & $0.8 \%$ & $65.4 \%$ \\
\hline & & & $\begin{array}{c}\text { No of } \\
\text { journals }\end{array}$ & $\begin{array}{c}\text { No of } \\
\text { outputs }\end{array}$ & $\begin{array}{c}\% \text { of } \\
\text { outputs }\end{array}$ & \\
\hline \multirow{3}{*}{\multicolumn{3}{|c|}{$\begin{array}{l}\text { ABS journals with }>=10 \text { papers in promotion portfolios } \\
\text { ABS journals with }<10 \text { papers in promotion portfolios } \\
\text { Total ABS journal inclusions }\end{array}$}} & 27 & 784 & $65 \%$ & \\
\hline & & & 179 & 415 & $35 \%$ & \\
\hline & & & 206 & 1199 & $100 \%$ & \\
\hline
\end{tabular}

Notes

1. Table in ranked order of descending journal 'popularity' 
Table7: Summary of outputs by subject area and in $4 *$ journals

\begin{tabular}{|l|c|c|c|}
\hline \multirow{2}{*}{ Subject area (as defined in ABS (2008)) } & \multicolumn{3}{|c|}{ All ABS journals } \\
\cline { 2 - 3 } & $\begin{array}{c}\text { No of } \\
\text { Journals }\end{array}$ & $\begin{array}{c}\text { No of } \\
\text { papers }\end{array}$ & $\begin{array}{c}\% \text { of ABS } \\
\text { papers }\end{array}$ \\
\hline
\end{tabular}

\begin{tabular}{|c|c|c|}
\hline \multicolumn{3}{|c|}{$4^{*}$ ABS journals } \\
\hline $\begin{array}{c}\text { No of } \\
\text { Journals }\end{array}$ & $\begin{array}{c}\text { No of } \\
\text { papers }\end{array}$ & $\begin{array}{c}\% \text { of ABS } \\
\text { papers }\end{array}$ \\
\hline
\end{tabular}

\begin{tabular}{|l|l|l|l|l|}
\hline Accounting and Finance $^{1}$ & A\&F & 79 & 828 & $69.1 \%$ \\
\hline
\end{tabular}

\begin{tabular}{|l|l|l|}
\hline 9 & 70 & $5.8 \%$ \\
\hline
\end{tabular}

\begin{tabular}{|l|l|c|c|c|}
\hline Management Development and Education & MAN DEV \& EDU & & 59 & $4.9 \%$ \\
\hline Economics & ECON & & 45 & $3.8 \%$ \\
\hline Public Sector Management & PUB SEC & & 41 & $3.4 \%$ \\
\hline Business Ethics and Corporate Governance & ETH-GOV & & 31 & $2.6 \%$ \\
\hline Business and Management History & BUS HIST & & 29 & $2.4 \%$ \\
\hline Management & GEN MAN & & 27 & $2.3 \%$ \\
\hline Social Sciences & SOC SCI & & 24 & $2.0 \%$ \\
\hline Entrepreneurship and Small Business & ENT-SMBUS & & 16 & $1.3 \%$ \\
\hline Management Science and OR & OPS RES \& MAN SCI & & 16 & $1.3 \%$ \\
\hline Operations and Technology Management & OPS \& TECH & & 14 & $1.2 \%$ \\
\hline Marketing & MKT & & 12 & $1.0 \%$ \\
\hline Strategic Management & STRAT & & 12 & $1.0 \%$ \\
\hline Sectoral Studies & SECTOR & 10 & $0.8 \%$ \\
\hline Information Systems and Management & INFO MAN & 7 & $0.6 \%$ \\
\hline Organization Studies & ORG STUD & & 6 & $0.5 \%$ \\
\hline International Business and Area Studies & IB \& AREA STUD & & 5 & $0.4 \%$ \\
\hline HRM and Employment Studies & HRM \& EMP STUD & & 4 & $0.3 \%$ \\
\hline Law & LAW & & 4 & $0.3 \%$ \\
\hline Psychology & PSYCH & & 4 & $0.3 \%$ \\
\hline Research and Innovation & INNOV & & $0.3 \%$ \\
\hline Toursim and Hospitality Management & TOUR-HOSP & 1 & $0.1 \%$ \\
\hline Total number of non-A\&F subject area papers & & $\mathbf{1 2 7}$ & $\mathbf{3 0 . 9 \%}$ \\
\hline
\end{tabular}

\begin{tabular}{|l|l|l|}
\hline 15 & 21 & $1.8 \%$ \\
\hline
\end{tabular}

Total number of ABS (2008) papers

206

$1 1 9 9 \longdiv { 1 0 0 . 0 \% }$

\begin{tabular}{lll}
\hline 24 & 91 & $7.6 \%$ \\
\hline \hline
\end{tabular}

$\mathrm{J}$ not listed in ABS08

Non-journal output

$\frac{823}{\mathbf{2 8 5 4}}$

Total number of outputs

Notes

1. One of the A\&F $4 *$ journals (Accounting, Organizations and Society) accounts for $60 \%$ (42 out of 70 ) of the A\&F $4 *$ papers 
Table 8: Journals from Glover et al.'s (2006) lists included within UK promotion portfolios

\begin{tabular}{|c|c|c|c|c|c|c|c|}
\hline Journal & ISSN & Subj group & $\begin{array}{c}\text { ABS } \\
\text { Grade } \\
\end{array}$ & $\begin{array}{c}\text { No of } \\
\text { papers } \\
\text { in } \mathbf{J} \\
\end{array}$ & $\begin{array}{c}\text { Glover } \\
\text { et al } \\
\end{array}$ & $\begin{array}{c}\text { No of } \\
\text { papers } \\
\text { in group } \\
\end{array}$ & $\begin{array}{c}\text { Cum } \\
\text { No } \\
\end{array}$ \\
\hline Accounting Review & $0001-4826$ & $\mathrm{~A} \& \mathrm{~F}$ & 4 & 1 & Acc03 & & \\
\hline Journal of Accounting \& Economics & $0165-4101$ & $\mathrm{~A} \& \mathrm{~F}$ & 4 & 2 & $\mathrm{Acc03}$ & & \\
\hline Journal of Accounting Research & $0021-8456$ & $\mathrm{~A} \& \mathrm{~F}$ & 4 & 4 & Acc03 & 7 & 7 \\
\hline Academy of Management Review & $0363-7425$ & GEN MAN & 4 & 1 & Bus & & \\
\hline Journal of Business Ethics & $0167-4544$ & ETH-GOV & 3 & 6 & Bus & & \\
\hline Journal of Finance & $0022-1082$ & $\mathrm{~A} \& \mathrm{~F}$ & 4 & 7 & Bus & & \\
\hline Journal of Financial Economics & 0304-405X & $\mathrm{A} \& \mathrm{~F}$ & 4 & 6 & Bus & & \\
\hline Journal of International Business Studies & 0047-2506 & IB \& AREA STUD & 4 & 1 & Bus & & \\
\hline Long Range Planning & 0024-6301 & STRAT & 3 & 5 & Bus & & \\
\hline MIS Quarterly & $0276-7783$ & INFO MAN & 4 & 2 & Bus & & \\
\hline RAND Journal of Economics & $0741-6261$ & ECON & 4 & 2 & Bus & & \\
\hline Review of Financial Studies & 0893-9454 & $\mathrm{A} \& \mathrm{~F}$ & 4 & 3 & Bus & 33 & 40 \\
\hline Accounting, Organizations and Society & 0361-3682 & $\mathrm{A} \& \mathrm{~F}$ & 4 & 42 & Acc06 & & \\
\hline Contemporary Accounting Research & $0823-9150$ & $\mathrm{~A} \& \mathrm{~F}$ & 2 & 2 & Acc06 & 44 & 84 \\
\hline Accounting Horizons & 0888-7993 & $\mathrm{A} \& \mathrm{~F}$ & 3 & 2 & Acc15 & & \\
\hline Auditing: a Journal of Practice \& Theory & $0278-0380$ & $\mathrm{~A} \& \mathrm{~F}$ & 2 & 2 & Acc15 & & \\
\hline Journal of Accounting, Auditing and Finance & $0148-558 X$ & $\mathrm{~A} \& \mathrm{~F}$ & 3 & 1 & Acc15 & & \\
\hline Journal of Accounting and Public Policy & $0278-4254$ & $\mathrm{~A} \& \mathrm{~F}$ & 3 & 6 & Acc15 & & \\
\hline Journal of Accounting Literature & $0737-4607$ & $\mathrm{~A} \& \mathrm{~F}$ & 3 & 1 & Acc15 & & \\
\hline Journal of Business Finance \& Accounting & 0306-686X & $\mathrm{A} \& \mathrm{~F}$ & 3 & 81 & Acc15 & 93 & 177 \\
\hline Abacus & 0001-3072 & $\mathrm{A} \& \mathrm{~F}$ & 2 & 7 & $\operatorname{Acc} 25$ & & \\
\hline Accounting and Business Research & $0001-4788$ & $\mathrm{~A} \& \mathrm{~F}$ & 3 & 78 & Acc25 & & \\
\hline Journal of Accounting Education & $0748-5751$ & MAN DEV \& EDU & 2 & 2 & $\operatorname{Acc} 25$ & & \\
\hline $\mathrm{J}$ of Management Accounting Research (AAA) & $1049-2127$ & $\mathrm{~A} \& \mathrm{~F}$ & 2 & 1 & Acc25 & & \\
\hline Review of Quantitative Finance and Accounting & 0924-865X & $\mathrm{A} \& \mathrm{~F}$ & 3 & 4 & Acc25 & 92 & 269 \\
\hline
\end{tabular}

Notes:

Acc03 = Top 3 Accounting

Bus = Through Top Business (top business journals in other disciplines but including the 3 accounting journals)

Acc06 = Through Top 6 Accounting (i.e. an extra 3 accounting journals added to the full business list)

Acc15 = Through Top 15 Accounting

Acc25 = Through Top 25 Accounting (includes 25 accounting plus 35 business journals making 60 journals in total) 